\title{
Intrinsic Plasticity of Cerebellar Purkinje Cells Contributes to Motor Memory Consolidation
}

\author{
${ }^{\circledR}$ Dong Cheol Jang, ${ }^{1,2 *}{ }^{\circledR}$ Hyun Geun Shim, ${ }^{2,3 *}$ and ${ }^{\circledR}$ Sang Jeong Kim ${ }^{1,2,3,4}$ \\ ${ }^{1}$ Department of Brain and Cognitive Science, College of Natural Science, Seoul National University, Seoul, Republic of Korea, 08826, ${ }^{2}$ Department of \\ Physiology, ${ }^{3}$ Department of Biomedical Sciences, and ${ }^{4}$ Neuroscience Research Institute, Seoul National University College of Medicine, Seoul, \\ Republic of Korea, 03080
}

Intrinsic plasticity of cerebellar Purkinje cells (PCs) has recently been demonstrated in cerebellar local circuits; however, its physiological impact on cerebellar learning and memory remains elusive. Here, we suggest that intrinsic plasticity of PCs is tightly involved in motor memory consolidation based on findings from PC-specific STIM1 knockout male mice, which show severe memory consolidation deficiency in vestibulo-ocular reflex memory. Gain-up training of the vestibulo-ocular reflex produced a decrease in the synaptic weight of PCs in both the WT and KO groups. However, intrinsic plasticity was impaired only in the knockout mice. Furthermore, the observed defects in the intrinsic plasticity of PCs led to the formation of aberrant neural plasticity in the vestibular nucleus neurons. Our results suggest that synergistic modulation of intrinsic and synaptic plasticity in PCs is required for the changes in downstream plasticity in the vestibular nucleus, and thereby contributing to the long-term storage of motor memory.

Key words: cerebellar motor learning; intrinsic plasticity; memory consolidation; system consolidation; vestibular nuclei; vestibulo-ocular reflex

\section{Significance Statement}

Synaptic plasticity is a well-known mechanism for learning and memory. Although plasticity of excitability, intrinsic plasticity, of the cerebellar Purkinje cell has been reported in both directions (potentiation and depression), the physiological role of intrinsic plasticity still remains ambiguous. In this study, we suggest that both synaptic and intrinsic plasticity are required for successful memory consolidation in cerebellar eye movement learning. Despite successful induction and maintenance of synaptic plasticity, we found deficits of memory consolidation when there were defects in intrinsic plasticity. Our results suggest that intrinsic plasticity of cerebellar Purkinje cell has a significant role in motor memory consolidation.

\section{Introduction}

It is widely believed that the cellular basis of memory is derived from modifications of synaptic transmission, such as LTP and

\footnotetext{
Received July 11, 2019; revised Mar. 26, 2020; accepted Mar. 30, 2020.

Author contributions: D.C.J., H.G.S., and S.J.K. designed research; D.C.J. and H.G.S. performed research; D.C.

J. and H.G.S. analyzed data; D.C.J. and H.G.S. wrote the first draft of the paper; D.C.J., H.G.S., and S.J.K. edited the paper; D.C.J., H.G.S., and S.J.K. wrote the paper.

This study was supported by a National Research Foundation of Korea Grant funded by the Korean government (2018R1A5A2025964 and 2017M3C7A1029611) to S.J.K., and Global PhD Fellowship Program 2013H1A2A1034318 to D.C.J. H.G.S. was supported by National Research Foundation of Korea BK21-Plus Education Program Scholarship 5262-20170100. We thank Seungha Kim and Yong Gyu Kim for experimental support; and Alexander Fanning, Trace Stay, Misun Mun, and Geehoon Chung for reviewing the draft.

The authors declare no competing financial interests.

*D.C.J. and H.G.S. contributed equally to this work.

D.C. Jang's present address: Neurorive Inc., Seoul BioHub 306, 117-3, Hoegi-ro, Dongdaemun-gu, Seoul, Korea, 02455 .

H.G. Shim's present address: Department of Neurobiology, Stanford University School of Medicine, Stanford, California, United States, 94305.

Correspondence should be addressed to Sang Jeong Kim at sangjkim@snu.ac.kr.

https://doi.org/10.1523/JNEUROSCl.1651-19.2020

Copyright $\odot 2020$ the authors
}

LTD (Kandel et al., 2014; Ryu et al., 2019). For decades since Ito (1982) proposed the flocculus hypothesis, numerous studies have demonstrated that synaptic plasticity between parallel fibers (PFs) and cerebellar Purkinje cells (PCs) is the key mechanism of vestibulo-ocular reflex (VOR) adaptation (Schonewille et al., 2010; Inoshita and Hirano, 2018; Kakegawa et al., 2018). However, several studies have proposed that synaptic plasticity at the PF-PC synapse is not sufficient to explain VOR learning (Wulff et al., 2009; Schonewille et al., 2011; Ito, 2013). Emerging evidence suggests that neural plasticity at multiple sites, including the cerebellar cortex and vestibular nucleus (VN), is required for VOR learning (Boyden et al., 2004; Porrill and Dean, 2007; Clopath et al., 2014; Yamazaki et al., 2015; Jang et al., 2019). Furthermore, it has been suggested that VOR memory is formed in cerebellar cortical areas through PF-PC plasticity at the early phase of adaption; and at late phase, plasticity occurs in VN (Ito, 2013). In VOR circuits, cerebellar PCs integrate the information and then project their output signal to the VN. Intriguingly, synaptic plasticity at mossy fibers (MFs) to VN neurons shows dependency on the activity of PCs (McElvain et al., 2010). This 
suggests that the activity-dependent modulation of the PC output might link between the plasticity at the neurons in the cerebellum and the $\mathrm{VN}$ to drive adequate memory formation. Indeed, the changes in intrinsic neuronal excitability (intrinsic plasticity) may integrate the synaptic inputs and determine the physiological ranges of neuronal output; furthermore, it has been suggested as an additional mechanism for memory storage (Daoudal and Debanne, 2003; Zhang and Linden, 2003; Shim et al., 2018). Together, the intrinsic plasticity is one plausible mechanism for linking between two brain areas (the cerebellum, VN); however, the impact of intrinsic plasticity on information storage is still elusive. We previously verified that the excitability of PCs shows bidirectionality in response to the different patterns of synaptic plasticity induction (Shim et al., 2017) and postulated that the intrinsic plasticity of PCs plays a role in VOR adaptation, based on former results (Ryu et al., 2017).

Here, we provide insight into the circuit mechanism through which intrinsic plasticity of cerebellar PCs may be required for long-term memory storage. We adopted a cerebellum-dependent oculomotor learning paradigm, and recorded both synaptic and intrinsic plasticity in cerebellar PCs and VN neurons. We also varied the time after training to understand when the critical time window for transduction is and what actually happens in this period. As a result, we found that both synaptic and intrinsic plasticity had been induced by the training in both regions. Furthermore, each plasticity showed different temporal dynamics through the post-training period. Simultaneously, we performed the same experiment in PC-specific stromal interaction molecule 1 (STIM1) knockout $\left(\mathrm{STIM} 1^{\mathrm{PKO}}\right.$ ), which has severe consolidation deficit (Ryu et al., 2017), to investigate the connections between plasticity at both brain regions with consolidation process. Interestingly, the STIM $1^{\text {PKO }}$ mice showed deficient intrinsic plasticity, although synaptic plasticity was induced after learning. Furthermore, neither synaptic plasticity nor intrinsic plasticity of the VN neurons was observed in STIM $^{\mathrm{PKO}}$ mice after training. This implies that the subsequent increases in the neural activity in the VN neurons may be derived from changes in cerebellar cortical output, as determined by the intrinsic plasticity of cerebellar PCs.

\section{Materials and Methods}

Animal model

We crossed a homozygous PCP2-Cre line (B6.129-Tg(Pcp2-cre)2Mpin/J line, The Jackson Laboratory) with a STIM1-floxed line (C57BL/6 background) to generate PC-specific STIM1 knockout line as reported in our recent study (Ryu et al., 2017). Only male mice were used in all experiments, and procedures were approved by the Institutional Animal Care and Use Committee of Seoul National University College of Medicine.

\section{Surgery}

All surgical procedures were similar to our previous paper (see Ryu et al., 2017). Surgery for head fixation was done on 7- to 8-week-olds. A Zoletil 50 (Virbac, $15 \mathrm{mg} / \mathrm{kg}$ ) + xylazine (Rompun, Bayer, $15 \mathrm{mg} / \mathrm{kg}$ ) mixture was intraperitoneally injected to anesthetize mice. Mice were given $24-48 \mathrm{~h}$ to recover after surgery.

\section{Behavior test}

The testing procedure was similar to our previous paper (see Ryu et al., 2017). To control pupil dilation, physostigmine salicylate solution (eserine; Sigma Millipore) was given to mice under brief isoflurane anesthetization. Mice were allowed to recover for least $20 \mathrm{~min}$ to wash out the side-effect of anesthetization. The concentration of eserine solution was increased from $0.1 \%, 0.15 \%$, and $0.2 \%$ based on the size of the pupil, which became larger due to drug resistance. Two sessions of acclimation were performed. At first, the mouse was fixed onto a restrainer for $15 \mathrm{~min}$ and experienced the light being turned on and off, or several brief visual and vestibular stimuli for checking whether there was any surgical failure. Second, a calibration procedure was performed. We measured three basal oculomotor responses: optokinetic reflex (OKR), VOR in the dark (dVOR), and VOR in the light (IVOR). Visual stimulation was provided by sinusoidally rotating a drum with $\pm 5^{\circ}$ for OKR. Vestibular stimulation was delivered by rotating the turntable so that the mouse sat on during dVOR and IVOR with the same rotation amplitude as OKR. The only difference between $\mathrm{dVOR}$ and IVOR was the light being off and on, respectively. Each response was recorded at four different rotating frequencies: $0.1,0.25,0.5$, and $1.0 \mathrm{~Hz}$. Associative visuo-vestibular stimulation was applied for gain-up training. The drum and table were simultaneously rotated out-of-phase with $\pm 5^{\circ}$ of amplitude. The protocol contained three $10 \mathrm{~min}$ training sessions and four checkups (Fig. $1 A$ ). Both groups showed normal basal oculomotor performance (Fig. $1 B, C)$. Trained mice went back to their home cages, which were placed in a completely dark condition until the next checkup; and after examining memory retention level, mice were killed for ex vivo recording. Presented stimulus and the eye movement responses were fit with sine curves. Gain was calculated as the ratio of the response amplitude to stimulus amplitude, and the phase differences between the two sine curves were determined as phase values. A custom-built LabView (National Instrument) analysis tool was used for all these procedures. The level of memory consolidation was calculated as a percentage of the retained memory divided by the peak learned memory.

\section{Slice preparation}

Coronal cerebellar (flocculus) and brainstem slices of $270-320 \mu \mathrm{m}$ were cut by a vibratome slicer (Leica Microsystems, VT1200) after behavioral testing of mice aged 9- to 11-week-old male mice. The brain was cut in ice-cold NMDG cutting solution containing the following (in $\mathrm{mM}$ ): 93 NMDG, 93 $\mathrm{HCl}, 2.5 \mathrm{KCl}, 1.2 \mathrm{NaH}_{2} \mathrm{PO}_{4}, 30 \mathrm{NaHCO}_{3}, 20$ HEPES, 25 glucose, 5 sodium ascorbate, 2 thiourea, 3 sodium pyruvate, $10 \mathrm{MgSO}_{4} \cdot 7 \mathrm{H}_{2} \mathrm{O}, 0.5 \mathrm{CaCl}_{2} \cdot 2 \mathrm{H}_{2} \mathrm{O}$, $\mathrm{pH}$ 7.3. All recordings from the flocculus were performed in the microzone where the floccular midline subregion was responsible for horizontal eye movement. The brainstem slices containing the $\mathrm{VN}$ were obtained from the more rostral part of the brain in which the brainstem was attached to the cerebellum. Slices were transferred to a recovery chamber containing NMDGcutting solution kept at $32^{\circ} \mathrm{C}$ for $10 \mathrm{~min}$, and then incubated at room temperature for an hour in standard aCSF containing the following (in $\mathrm{mM}$ ): $125 \mathrm{NaCl}, 2.5 \mathrm{KCl}, 1 \mathrm{MgCl}_{2}, 2 \mathrm{CaCl}_{2}, 1.25 \mathrm{NaH}_{2} \mathrm{PO}_{4}, 26 \mathrm{NaHCO}_{3}$, and 10 glucose. NMDG-cutting solution and aCSF were oxygenated with $95 \% \mathrm{O}_{2} /$ $5 \% \mathrm{CO}_{2}, \mathrm{pH} 7.4$. All recordings in the $\mathrm{VN}$ were performed in the parvocellular region, which largely receives the output of flocculus directly (Matsuno et al., 2016).

\section{Whole-cell recording}

Brain slices were placed in a recording chamber on the stage of an Olympus microscope (BX50WI) and perfused with standard aCSF. We used an EPC9 amplifier with PatchMaster software (HEKA Elektronik) and multiclamp 700B amplifier with pClamp 10 (Molecular Devices) for amplification of recorded signals. The sampling frequency was $20 \mathrm{kHz}$, and signals were filtered at $2 \mathrm{kHz}(1 \mathrm{kHz}$ filter for sEPSC). Inhibitory synaptic inputs were totally blocked by $100 \mu \mathrm{M}$ picrotoxin (Sigma Millipore) during PC recordings, and strychnine $(1 \mu \mathrm{M})$ was added to block glycinergic input in $\mathrm{VN}$ recordings. Patch pipettes (3-4 M $\Omega$ ) were pulled from borosilicate glass and filled with internal solution containing the following (in $\mathrm{mM}$ ): $9 \mathrm{KCl}, 10 \mathrm{KOH}, 120 \mathrm{~K}$-gluconate, $3.48 \mathrm{MgCl}_{2}, 10$ HEPES, $4 \mathrm{NaCl}, 4 \mathrm{Na}_{2} \mathrm{ATP}, 0.4 \mathrm{Na}_{3} \mathrm{GTP}$, and 17.5 sucrose, $\mathrm{pH} 7.25$, for testing in vitro recordings, ex vivo PC excitability, and ex vivo $\mathrm{VN}$ recordings. For ex vivo sEPSC recording from PCs in the medial part of the flocculus, the following internal solution was used (in $\mathrm{mM}$ ): 140 $\mathrm{CsCl}, 4 \mathrm{NaCl}, 0.5 \mathrm{CaCl}_{2}, 10 \mathrm{HEPES}, 2 \mathrm{MgATP}$, and 5 EGTA, pH 7.3. For ex vivo eEPSC recording from PCs, we placed the stimulating electrode to one-third from outer edge of molecular layer and obtained data by stimulating three different sites of PF beam and calculating the average value to avoid bias. PF stimulation intensity varied from 10 to $50 \mu \mathrm{A}$ with $10 \mu \mathrm{A}$ increments, and each stimulation interval was $30 \mathrm{~s}$. To evaluate the excitability of the cerebellar PCs, we compared gain responses of the neurons. We injected a series of square-wised current steps ranging from 100 to $600 \mathrm{pA}$ with increments of $100 \mathrm{pA}$ for $500 \mathrm{~ms}$. The membrane potential of the cerebellar PCs was held at $-70 \mathrm{mV}$ by injecting 
A
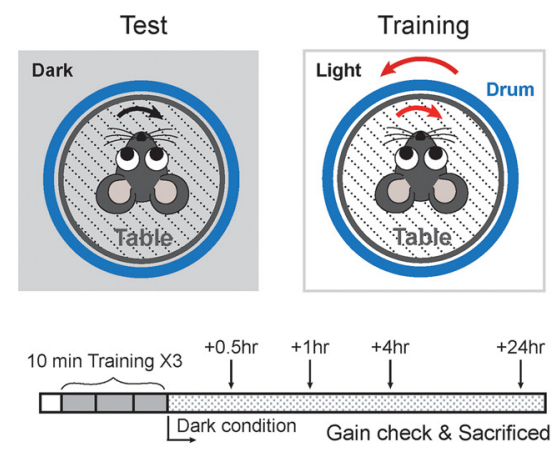

B

OKR

dVOR

IVOR
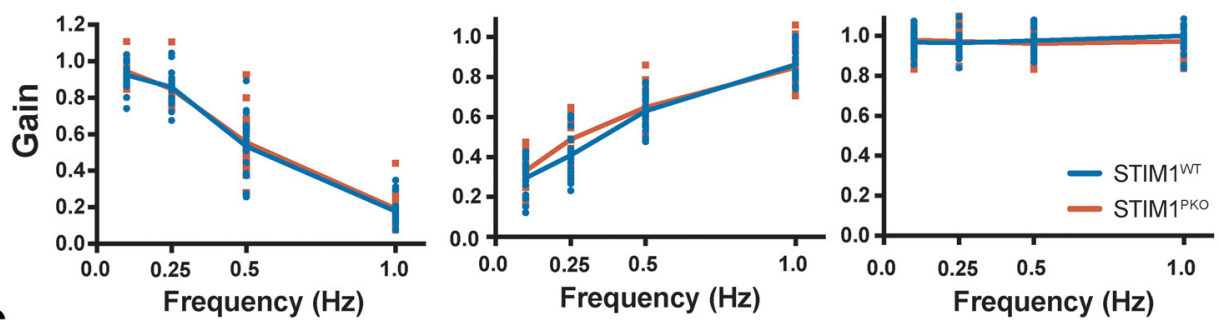

C
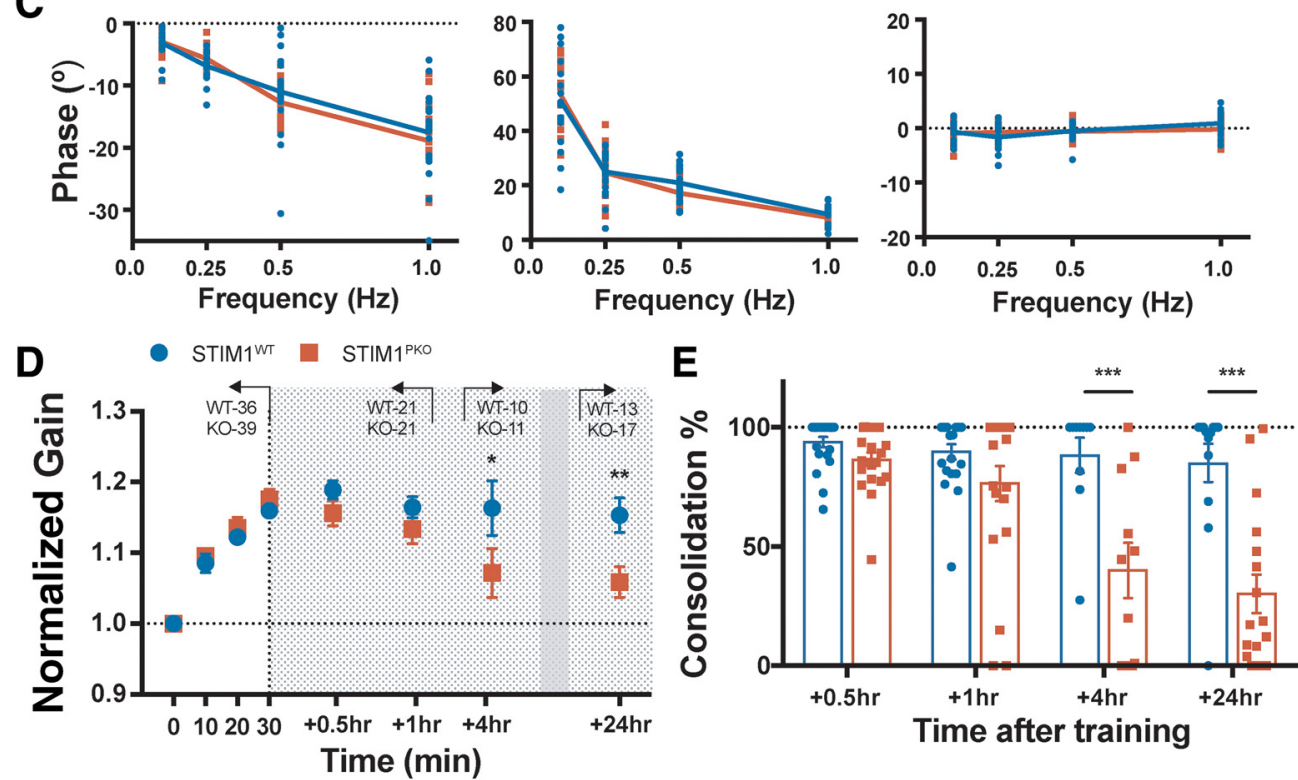

Figure 1. Long-term memory storage is impaired in STIM1 ${ }^{\mathrm{PKO}}$ mice. $A$, Illustration of the VOR test and training (top) and experimental scheme (bottom). For training, visuo-vestibular stimulation was delivered through a drum and turntable in 10 min sessions for three times; dVOR at $0.5 \mathrm{~Hz}$ was recorded before the learning and after each session of training. After completing a whole training session, animals were put in the completely dark condition. $\boldsymbol{B}$, Gain values of OKR (left), dVOR (middle), and IVOR (right) in various frequencies of drum rotation. There were no significant differences between genotypes (WT, $n=20 ;$ STIM1 $^{\text {PKO }}, n=17$ ). C, Phase values of OKR (left), dVOR (middle), and IVOR (right) in various frequencies of drum rotating. There were no significant differences between genotypes (WT, $n=20 ;$ STIM1 $^{\text {PKO }}, n=17$ ). $\boldsymbol{D}$, Normalized gain of the eye movement in learning. There is no significant difference between WT and STIM1 $1^{\mathrm{PKO}}$ mice in learning (points on white background; WT, $n=36 ;$ STIM1 $^{\text {PKO }}, n=39$ ). We measured memory retention level at 0.5 and $1 \mathrm{~h}$ (described as short-term; WT, $n=21 ;$ STIM1 $^{\text {PKO }}, n=21$ ), 4 $\mathrm{h}$ (mid-term; WT, $n=10 ; \mathrm{STIM1}^{\mathrm{PK} 0}, n=11$ ) and $24 \mathrm{~h}$ (long-term period; WT, $n=13 ; \mathrm{STIM1}^{\mathrm{PKO}}, n=17$ ) after training (points on gray-dotted background). STIM1 ${ }^{\mathrm{PK} 0}$ showed significantly lower memory retention level from the mid-term period compared with the WT littermates ( $4 \mathrm{~h}, p=0.037 ; 24 \mathrm{~h} ; p=0.004)$. E, Calculated consolidation level. Memory retention level was obtained by calculating the ratio remaining to the level of learned memory $(4 \mathrm{~h}, p<0.001 ; 24 \mathrm{~h}, p<0.001)$. $\boldsymbol{D}$, Two-way repeated-measures ANOVA. $\boldsymbol{E}$, Unpaired $t$ test. Error bars indicate SEM. ${ }^{* * *} p<0.001$; post hoc Sidak test for pairwise comparison.

bias current in current-clamp mode. To measure the excitability of VN neurons, we injected from $-150 \mathrm{pA}$ to $150 \mathrm{pA}$ current with increments of $50 \mathrm{pA}$ for $1 \mathrm{~s}$. All recordings were done at room temperature. There was no bias current in current-clamp mode to hold the membrane potential at these recordings. All patch-clamp data, except for sEPSC recordings, were imported and analyzed by Igor Pro (Wave Metrics). The sEPSC data were analyzed using Mini Analysis (Synaptosoft). Other recording and analysis details, including the plasticity induction protocol, were similar to our previous paper (see Shim et al., 2017).
Statistical analysis

As we described above, behavioral data were analyzed by a custom-built LabView (National Instrument) tool, and electrophysiology data were analyzed by Igor Pro (Wave Matrics) and Mini Analysis (Synaptosoft). All statistical analyses were performed using Graphpad Prism 7 and Microsoft Excel. A one-way ANOVA, including repeated-measures, with post hoc Dunnett test, and two-way repeated-measures ANOVA with Sidak's post hoc test, was used for group comparisons. Kolmogorov-Smirnov tests were used for cumulative group comparison. 
A

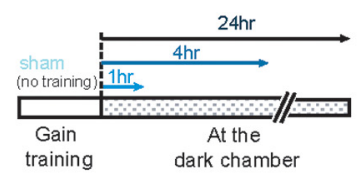

D

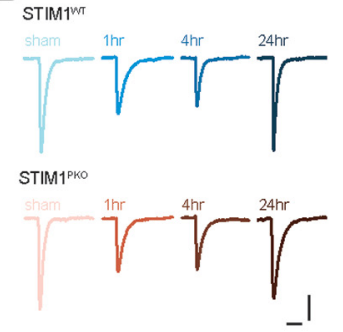

G

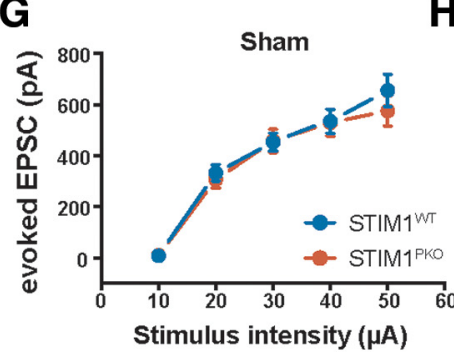

B

E

H
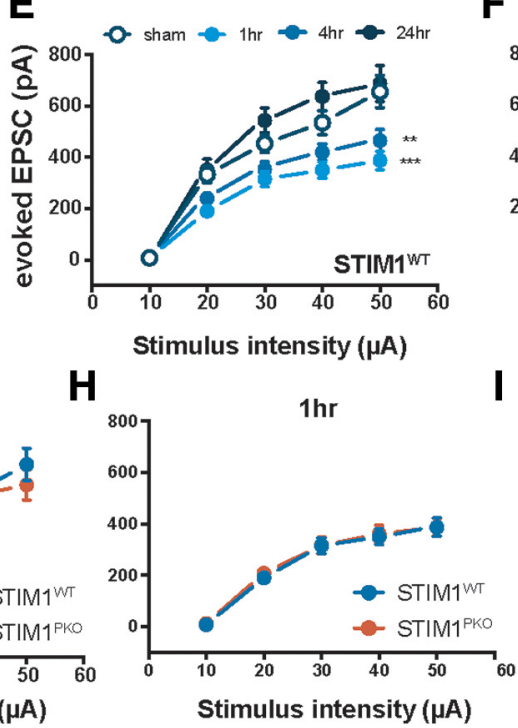

C

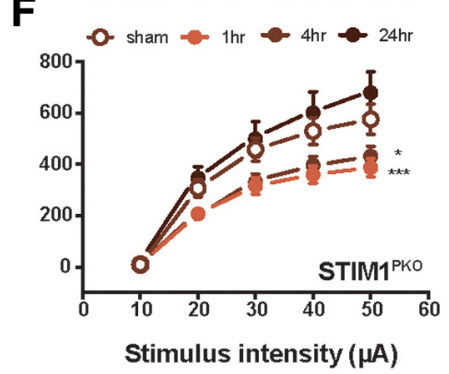

I

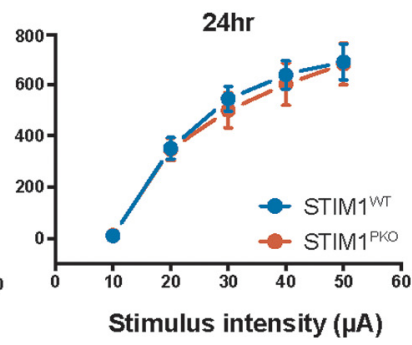

Figure 2. Reduced responses of PF-PC synapses after gain-up learning. $\boldsymbol{A}$, Experimental scheme. The floccular slices were made 1,4 , and $24 \mathrm{~h}$ after VOR gain-up training, and sham animal underwent the same procedure to experimental groups without training session. $\boldsymbol{B}$, Illustration of the flocculus. We placed stimulating electrode to one-third from the top of molecular layer. The electrophysiological recordings were performed from the PCs located at the H zone. C, Image showing the recording sites. $\boldsymbol{D}$, Representative eEPSC traces of both genotype groups at each time point. Calibration: $200 \mathrm{pA}, 30 \mathrm{~ms}$. $\boldsymbol{E}$, Amplitude of eEPSC by serial PF stimulation in WT littermates. In comparison with sham group $(n=9)$, amplitude was significantly reduced at 1 and $4 \mathrm{~h}$ after learning (at $50 \mu \mathrm{A}$ injection; $1 \mathrm{~h}, n=19, p<0.001 ; 4 \mathrm{~h}, n=9, p=0.002$ ), and depressed amplitude was recovered $24 \mathrm{~h}$ later (at $50 \mu \mathrm{A}$ injection; $24 \mathrm{~h}, n=8, p=0.922$ ). $\boldsymbol{F}$, Amplitude of eEPSC by serial PF stimulation in STIM1 ${ }^{\mathrm{PKO}}$. As with WT littermates, the amplitude was considerably decreased at 1 and $4 \mathrm{~h}$ later, and restored at $24 \mathrm{~h}$ after learning (at $50 \mu \mathrm{A}$ injection; sham, $n=14 ; 1 \mathrm{~h}, n=14, p<0.001 ; 4 \mathrm{~h}, n=14, p=0.013 ; 24 \mathrm{~h}, n=7, p=0.232)$. G, Comparison of eEPSC in sham group from both genotypes. In sham group, amplitude of eEPSC in STIM1 ${ }^{\text {WT }}$ was compatible to STIMP ${ }^{\text {PKO }}$. $\boldsymbol{H}$, Comparison of eEPSC at $1 \mathrm{~h}$ after training from both genotypes. In this $1 \mathrm{~h}$ group time point, amplitude of eEPSC in STIM1 ${ }^{\mathrm{WT}}$ was comparable with STIM1 ${ }^{\text {PKO }}$. I, Comparison of eEPSC at $24 \mathrm{~h}$ after training group in both genotypes. In this time point, amplitude of eEPSC in STIM1 ${ }^{\text {WT }}$ was comparable with STIM1 ${ }^{\text {PKO }}$. $\boldsymbol{E}, \boldsymbol{F}$, Two-Way repeated-measures ANOVA. Asterisks at each time points were calculated by compared with sham groups. Error bars indicate SEM. ${ }^{*} p<0.05 ;{ }^{* *} p<0.01 ;{ }^{* * *} p<0.001 ;$ post hoc Sidak test for pairwise comparison.

Unpaired $t$ test and Mann-Whitney $U$ test were used to compare WT and $\mathrm{KO}$ groups. All graphs are shown as mean \pm SEM. Detailed statistical methods and $n$ for each experiment are written in the figure legends.

\section{Results}

\section{Consolidation deficit in the STIM1 ${ }^{\text {PKO }}$ mouse may occur between 1 and $4 \mathrm{~h}$ after learning}

Accumulating evidence supports the theory that gain change of eye movement is attributed by the plasticity in the cerebellar cortex and the brainstem (Kassardjian et al., 2005; Okamoto et al., 2011a,b; Ito, 2013). This sequential memory acquisition within the cortex and brainstem has been implicated in long-term memory storage. Interestingly, Okamoto et al. (2011a) observed that memory transfer occurs between 2.5 and $4 \mathrm{~h}$ after learning in mice. This implies that this period of time is the critical period for communication between the cerebellar cortex and subcortical areas (in this circumstance, the VN). Since we have previously reported that an impairment in long-term memory storage, but not memory acquisition, is observed in the STIM $1{ }^{\text {PKO }}$ mice (Ryu et al., 2017), we hypothesized that a dysfunctional communication between the cerebellum and the VN would manifest a consolidation deficit in this model. To address this, we selected three periods after the learning task had finished in which measurements were made: two points as short-term period (at 0.5 and $1 \mathrm{~h}), 4 \mathrm{~h}$ as the mid-term period, and $24 \mathrm{~h}$ as the longterm period. The memory retention level was evaluated at each of these periods. The learning and memory retention at the short-term period were comparable between genotypes (Fig. $1 D)$. However, at the mid-term period, the memory retention level was significantly lower in the STIM1 ${ }^{\mathrm{PKO}}$ group than in the WT group. Furthermore, at the long-term period, memory retention was eliminated in the STIM1 ${ }^{\text {PKO }}$ group (Fig. 1D). This temporal alteration in the memory retention level was recalculated as the ratio of the remaining memory at the test session to the acquired memory at the training session (Fig. 1E). These results revealed a gradual reduction in memory retention over the studied periods. Given that the slight decline in the level of memory retention began $1 \mathrm{~h}$ after the learning task and developed further, we speculated that the impaired motor memory consolidation that was observed in the STIM1 ${ }^{\mathrm{PKO}}$ mice was based on defect of memory process during mid-term period.

Learning induces PF-PC synaptic plasticity in both groups

Many previous studies, using various LTD-deficient animal models, have reported that synaptic plasticity at the PF-PC synapse is strongly correlated with VOR learning (Boyden et al., 
A

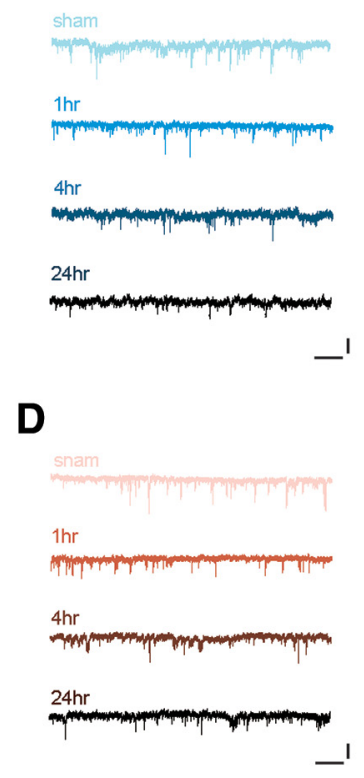

B

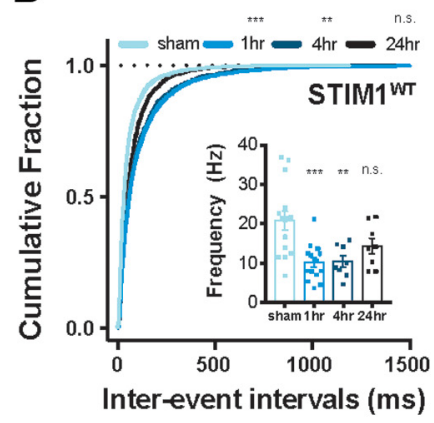

E

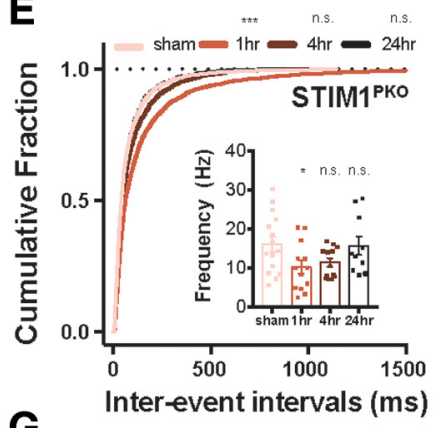

G

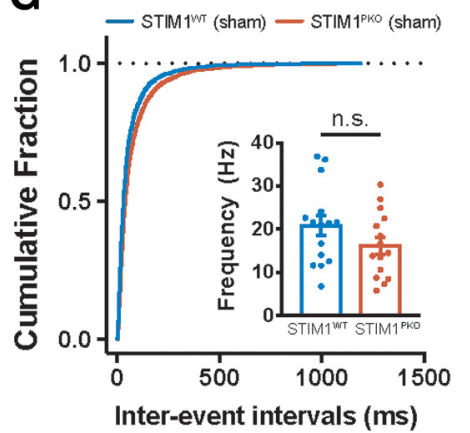

C

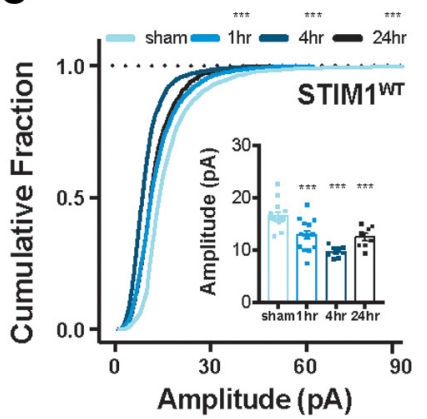

F

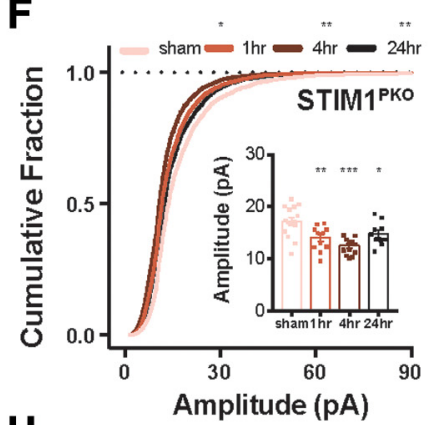

H

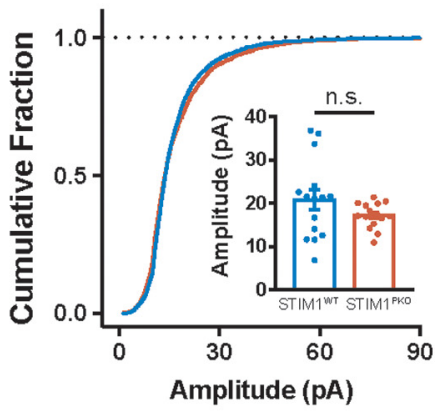

Figure 3. LTD at the PF-PC synapses after gain-up learning. A, Representative sEPSC traces of WT group at each time point. Calibration: $25 \mathrm{pA}, 1 \mathrm{~s}$. B, Cumulative plots of IEE of $s E P S C$ in WT littermates (sham, $n=15 ; 1 \mathrm{~h}, n=15 ; 4 \mathrm{~h}, n=8 ; 24 \mathrm{~h}, n=8$ ). The cumulative fractions of learning groups were right-shifted compared with sham groups, implying reduction of frequency (1 $\mathrm{h}, p<0.001 ; 4 \mathrm{~h}, p=0.002 ; 24 \mathrm{~h}, p=0.872)$. Inset, Bar graph represents mean frequencies of sEPSC indicating depression of frequency $(1 \mathrm{~h}, p<0.001 ; 4 \mathrm{~h}, p=0.002 ; 24 \mathrm{~h}, p=0.074)$. C, Cumulative plots of amplitude of SEPSC in WT littermates. The cumulative fractions of learning groups were left-shifted compared with sham groups, implying reduction of amplitude (1 h, $p<0.001 ; 4 \mathrm{~h}, p<0.001 ; 24 \mathrm{~h}, p<0.001)$. Inset, Bar graph represents mean amplitudes of sEPSC, indicating that depression of amplitude was maintained for $24 \mathrm{~h}$ after learning (1 h, $p<$ $0.001 ; 4 \mathrm{~h}, p<0.001 ; 24 \mathrm{~h}, p<0.001)$. D. Representative sEPSC traces of STIM ${ }^{\mathrm{PKO}}$ group at each time point. Calibration: $25 \mathrm{pA}, 1 \mathrm{~s}$. E, Cumulative plots of IEl of sEPSC in STIM ${ }^{\mathrm{PKO}}$ mice (sham, $n=15 ; 1 \mathrm{~h}, n=13 ; 4 \mathrm{~h}, n=13 ; 24 \mathrm{~h}, n=10)$. The cumulative fraction of $1 \mathrm{~h}$ after learning was right-shifted $(1 \mathrm{~h}, p<0.001)$, but most of changes returned to sham level from 4 and $24 \mathrm{~h}$ after training ( $4 \mathrm{~h}, p=0.998 ; 24 \mathrm{~h}, p=0.405)$. Inset, Summarizing bar graph of $s$ EPSC frequency, implying that frequency of sEPSC was transiently depressed at $1 \mathrm{~h}$ and recovered from $4 \mathrm{~h}$ after learning $(1 \mathrm{~h}, p=0.048 ; 4 \mathrm{~h}, p=0.131 ; 24 \mathrm{~h}, p=0.997)$. $\boldsymbol{F}$, Cumulative plots of amplitude of sEPSC in STIM ${ }^{\mathrm{PKO}}$ mice. The cumulative fractions of learning groups were more left-shifted than sham groups $(1 \mathrm{~h}, p=0.041 ; 4 \mathrm{~h}, p=0.003 ; 24 \mathrm{~h}, p=0.003)$. Inset, Bar graph represents that amplitude of sEPSC was depressed and maintained for $24 \mathrm{~h}$ after learning $(1 \mathrm{~h}, p=0.003$; $4 \mathrm{~h}, p<0.001 ; 24 \mathrm{~h}, p=0.040$ ). G, Cumulative plots of IEI of SEPSC in WT (blue, $n=15$ ) and STIM1 ${ }^{\text {PKO }}$ mice (red, $n=15$ ). The cumulative fraction of IEl and bar graph (inset) of $s E P S C$ frequency indicated that frequency of SEPSC was not changed in STIM1 ${ }^{\text {PKO }}$ compared with WT littermates (cumulative plot, $p=0.370$; bar graph, $p=0.145$ ). $\boldsymbol{H}$, Cumulative plots of amplitude of SEPSC. The cumulative fraction of amplitude and bar graph (inset) of sEPSC frequency indicated that amplitude of SEPSC was not changed in STIM1 ${ }^{\text {PKO }}$ compared with WT littermates (cumulative plot, $p=0.998$; bar graph, $p=0.587)$. $\boldsymbol{B}, \boldsymbol{C}, \boldsymbol{E}-\boldsymbol{H}$, Kolmogorov-Smirnov test was used for comparing cumulative plots. $\boldsymbol{B}, \boldsymbol{C}, \boldsymbol{E}, \boldsymbol{F}$, One-way ANOVA with post hoc Dunnett test was used for inset bar graphs. $\mathbf{G}, \boldsymbol{H}$, Unpaired $t$ test was used for inset bar graphs. Error bar indicates SEM. Asterisks at each time points were calculated by comparing to sham groups. Error bars indicate SEM. ${ }^{*} p<0.05 ;{ }^{* *} p<0.01 ;{ }^{* * *} p<0.001$. n.S., not significant.

2006). It has recently been reported that OKR adaptation leads synaptic LTD in the cerebellar cortex. (Inoshita and Hirano, 2018), but plasticity induced by VOR adaptation has yet to be shown with direct evidence. Late-phase LTD has also been implicated in VOR memory consolidation (Boyden et al., 2006). This result suggests that a learning-related long-lasting reduction of cerebellar cortical activity affects the consolidation of memory. Interestingly, because the time course of late-phase LTD is similar to that of the mid-term period of study, we investigated whether PF-PC LTD is involved in memory consolidation. To verify this in detail, electrophysiological ex vivo recordings were made from floccular PCs to investigate the signs of synaptic plasticity at the short-, mid-, and long-term periods after learning task (Fig. 2A). This approach enabled monitoring neuronal activity for periods of over an hour, overcoming the experimental limitation of the whole-cell patch-clamp technique. Because of the location of the microzone of the flocculus that regulates horizontal VOR behavior, we recorded from PCs that were located in the medial part of the flocculus (Fig. 2B,C) (Schonewille et al., 2006). As a control group, we used sham animals that had undergone surgery and restraint without the learning task. We first measured the PF-evoked synaptic response (eEPSC) following the 
A

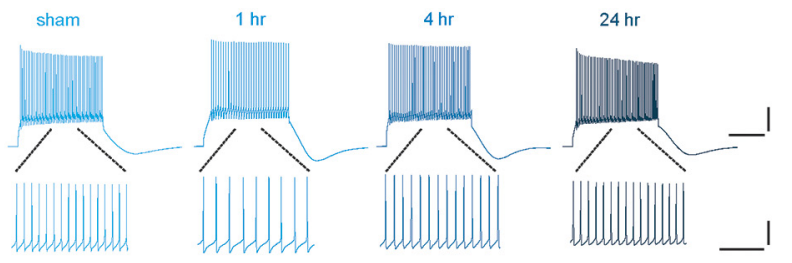

B

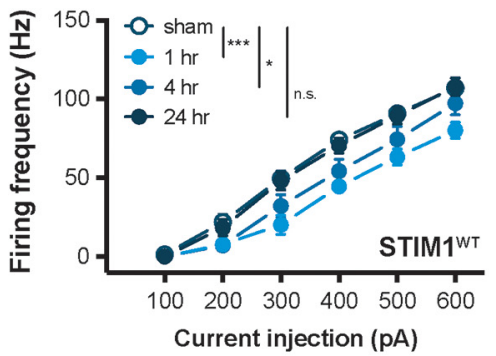

C

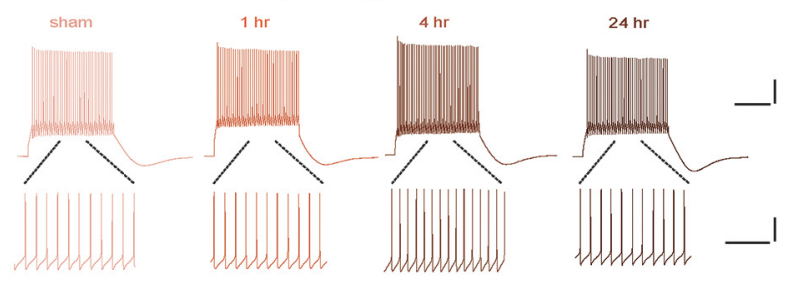

D

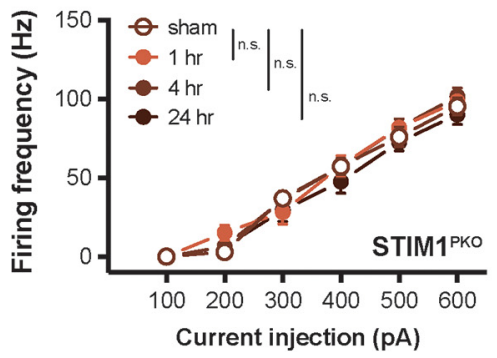

E

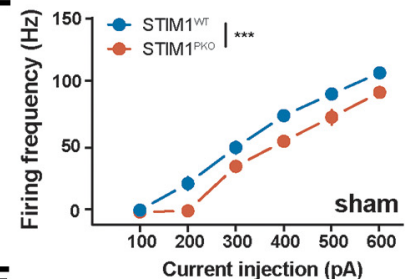

$F$
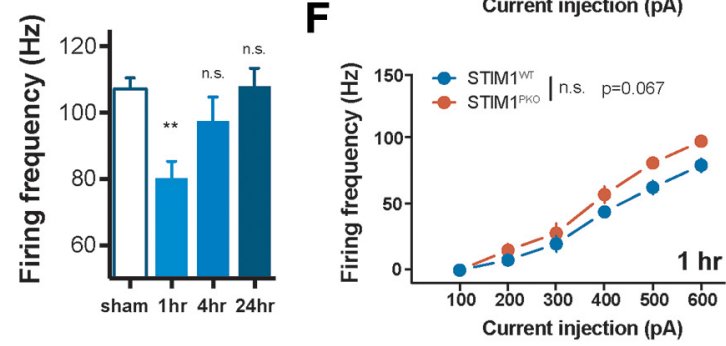

G

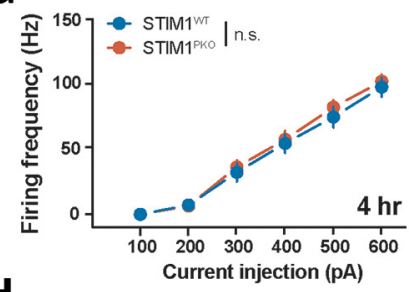

H
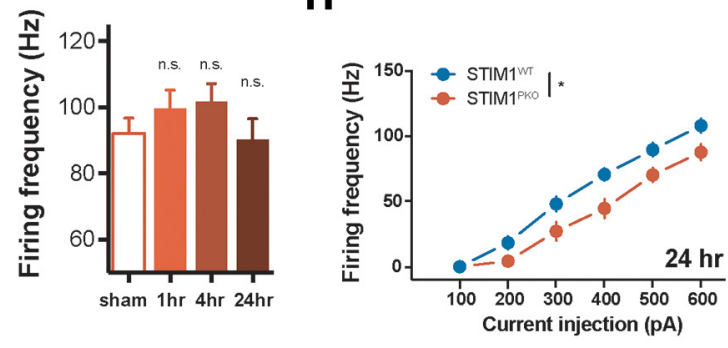

Figure 4. VOR adaptation also induces plastic change of IE in PCs. A, Representative traces from whole-cell recording in WT group. Calibration (top): $20 \mathrm{mV}, 200 \mathrm{~ms}$. Calibration (bottom): $20 \mathrm{mV}, 50 \mathrm{~ms}$. B, PC excitability of WT littermates over several time points. VOR adaptation decreased gain responses of the cerebellar PCs in response to square-wave current injection ranging from 100 to $600 \mathrm{pA}$ for $500 \mathrm{~ms}$ (sham vs $1 \mathrm{~h}, p<0.001$; sham vs $4 \mathrm{~h}, p=0.024$; sham vs $24 \mathrm{~h}, p=0.717$, left; sham, $n=20 ; 1 \mathrm{~h}, n=11 ; 4 \mathrm{~h}, n=16 ; 24 \mathrm{~h}, n=20$ ). Excitability in $600 \mathrm{pA}$ injection was significantly decreased at short-term $(1 \mathrm{~h}, p=0.006)$, mostly recovered at mid-term $(4 \mathrm{~h}, p=0.424)$, and fully recovered at long-term $(24 \mathrm{~h}, p=0.999)$. C, Representative traces from whole-cell recording in STIM1 ${ }^{\mathrm{PKO}}$ group. Calibration (top), $20 \mathrm{mV}, 200 \mathrm{~ms}$. Calibration (bottom), $20 \mathrm{mV}, 50 \mathrm{~ms}$. D. Excitability of PC in STIM1 ${ }^{\mathrm{PKO}}$. Different from WT littermates, STIM1 ${ }^{\mathrm{PK} 0}$ showed no alteration of excitability after learning (sham vs $1 \mathrm{~h}, p=0.370$; sham vs $4 \mathrm{~h}, p=0.343$; sham vs $24 \mathrm{~h}, p=0.768$, left; sham, $n=17 ; 1 \mathrm{~h}, n=13 ; 4 \mathrm{~h}, n=17 ; 24 \mathrm{~h}, n=13$ ). There were no significant changes in $600 \mathrm{pA}$ injection $(1 \mathrm{~h}, p=0.696 ; 4 \mathrm{~h}, p=0.401 ; 24 \mathrm{~h}, p=0.991)$. E, STIM1 ${ }^{\mathrm{PKO}}$ group $(n=17)$ showed significantly lower excitability than WT littermates $(n=20, p<0.001)$. $\boldsymbol{F}$, While the excitability of $\operatorname{STIMP}^{\mathrm{PKO}}(n=13)$ was unchanged, excitability of WT littermates $(n=11)$ was decreased $(p=0.067)$. G, At $4 \mathrm{~h}$ after learning, the altered excitability of WT littermates $(n=16)$ partly restored, and overlapped to excitability of $\operatorname{STIMI}^{\mathrm{PKO}}(n=17)$, which was still unchanged $(p=0.644)$. $\boldsymbol{H}$, As the excitability of WT littermates $(n=20)$ was fully recovered, significant difference from STIM ${ }^{\text {PKO }}$ group $(n=13)$ was also restored $(p=0.022)$. $\boldsymbol{B}, \boldsymbol{D}$-H, Two-way repeated-measures ANOVA with post hoc Sidak test was used for injected current-frequency and bar graphs. B, D, One-way ANOVA with post hoc Dunnett test was used for bar graphs. Asterisks at each time points were calculated by comparing with sham groups. Error bars indicate SEM. ${ }^{*} p<0.05 ;{ }^{* *} p<0.01 ;{ }^{* *} p<0.001$. n.s., not significant.

injection of a range of electrical stimuli intensities. In these experiments, the amplitude of the eEPSC had decreased at the short-term $(1 \mathrm{~h})$ and mid-term $(4 \mathrm{~h})$ period compared with the sham group. However, this alteration was recovered, with the eEPSC amplitude returning to a level that was not significantly different from that of sham control before the long-term phase in both groups (Fig. 2D-F). Comparison between genotypes showed no statistical differences among the experimental subgroups (Fig. 2G-I). We further investigated whether the VOR learning alters spontaneous synaptic activity, by recording the sEPSC after the learning task. Between the sham groups of both genotypes, there was no significant difference in spontaneous glutamatergic synaptic transmission (Fig. 3). The distribution of the interevent intervals (IEIs) of synaptic events was shifted to the right after the learning task and was restored at the long- term period in both groups (Fig. $3 B, E$ ). However, the mean frequency of sEPSC in the STIM $1{ }^{\mathrm{PKO}}$ mice was transiently reduced until $1 \mathrm{~h}$ after the learning task, and was recovered at $4 \mathrm{~h}$; whereas in WT littermates, the change was constantly maintained until $4 \mathrm{~h}$ and slightly recovered $24 \mathrm{~h}$ after the learning task (Fig. $3 B, E$ ). In contrast, the aspect of changes in the sEPSC amplitudes in the STIM1 ${ }^{\mathrm{PKO}}$ mice was comparable with that of the WT littermates (Fig. 3C,F). In both groups, the distribution of the sEPSC amplitude was left-shifted after the learning task, and this change was maintained until the long-term period. Collectively, these results, as well as the results of a previous study (Boyden et al., 2006), indicate that VOR gain-up training elicited synaptic weakening of the PF-PC synapses. Among genotypes, there were no significant differences in the distribution and amplitude of spontaneous synaptic activity (Fig. 3G,H). 
A
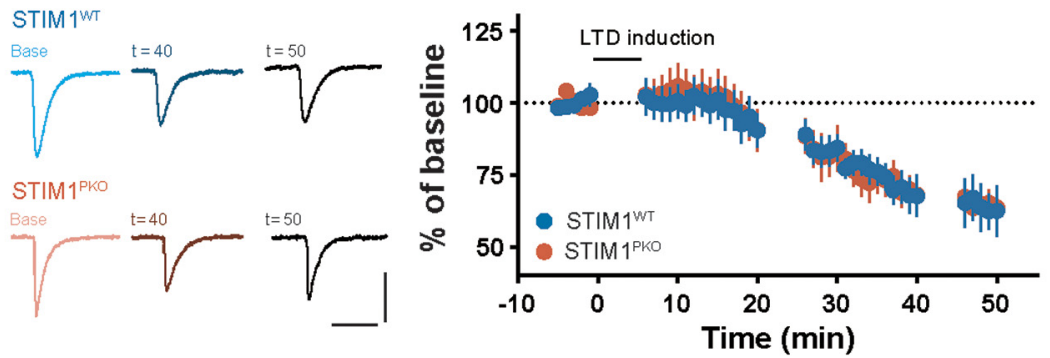

B
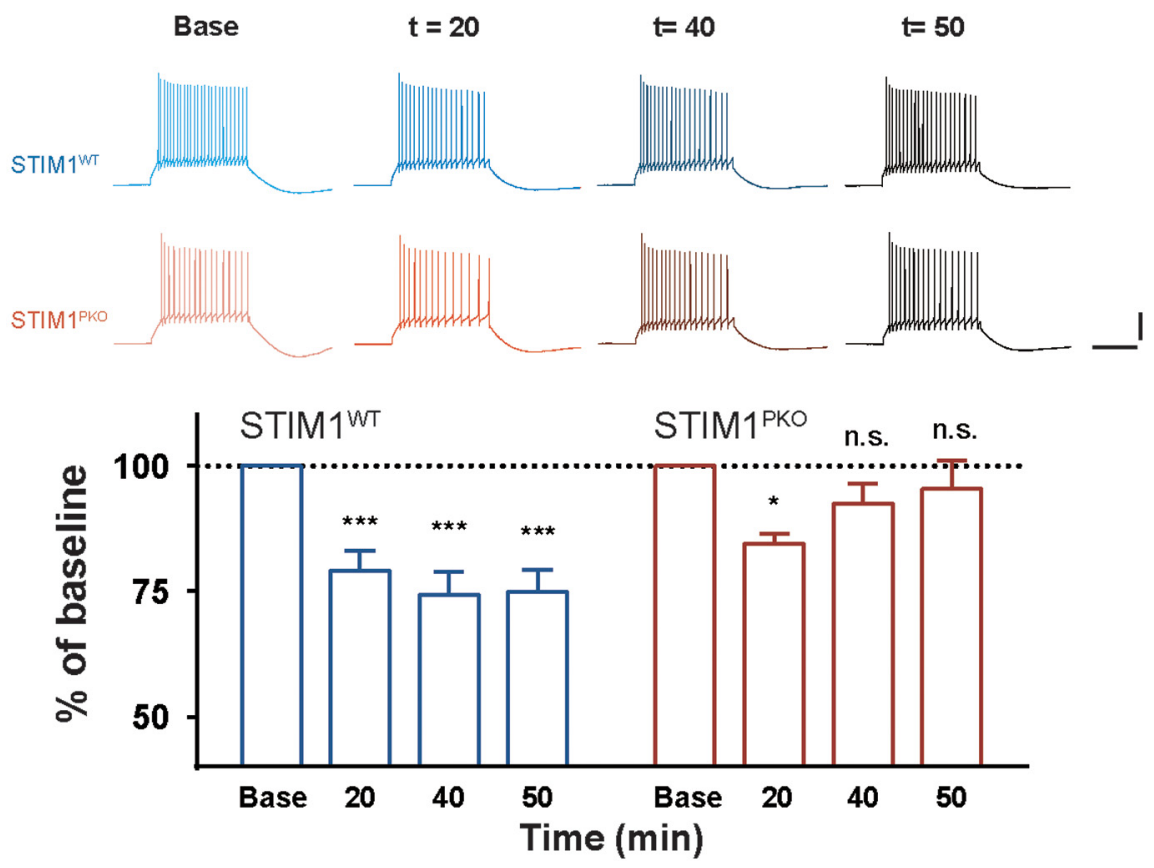

Figure 5. Intrinsic plasticity, but not synaptic plasticity, was impaired in STIM1 ${ }^{\mathrm{PKO}}$. A, Plots of the normalized EPSC change after application of LTD induction protocol in WT littermates $\left(n=8, n=4\right.$ after $40 \mathrm{~min}$, blue) and STIMP ${ }^{\mathrm{PKO}}$ mice $(n=7$, $n=6$ after $40 \mathrm{~min}$, red). Synaptic plasticity was normally induced in both genotype groups. Calibration: $200 \mathrm{pA}, 50 \mathrm{~ms}$. B, Bar graphs represent the comparison of excitability changes after LTD induction. In STIM ${ }^{\mathrm{PKO}}$ mice, downregulation of excitability in PCs was shown 20 min after induction $(n=7, p=0.009)$; however, it had fully recovered 40 and 50 min after induction ( $40 \mathrm{~min}, n=7, p=0.286 ; 50 \mathrm{~min}, n=6, p=0.690$ ). On the contrary, the intrinsic plasticity was induced and slightly further developed in time from WT littermates ( $20 \mathrm{~min}, n=8, p<0.001 ; 40 \mathrm{~min}, n=8, p<0.001 ; 50 \mathrm{~min}, n=4, p<0.001$ ). Calibration: $20 \mathrm{mV}, 200 \mathrm{~ms}$. B, One-way repeated-measures ANOVA with post hoc Dunnett correction. ${ }^{*} p<0.05$; ${ }^{* * *} p<0.001$. n.s., not significant.

Although the alterations of sEPSC frequency that were observed in the STIM1 ${ }^{\mathrm{PKO}}$ mice were relatively transient compared with the results observed in the WT group, the plasticity that was induced by VOR adaptation was similar between the groups. Therefore, we suggest that the PF-PC LTD induced by learning presumably did not contribute to the long-term memory deficit observed in the STIM1 ${ }^{\mathrm{PKO}}$ mice.

\section{Learning-related intrinsic plasticity shows relevance in memory consolidation}

An experience-dependent neural plasticity includes not only synaptic plasticity but also alterations in intrinsic excitability (IE) (Daoudal and Debanne, 2003; Zhang and Linden, 2003). Because PF-PC LTD was not sufficient to account for the memory consolidation deficit in STIM1 ${ }^{\mathrm{PKO}}$ mice, we hypothesized whether intrinsic plasticity, another form of neural plasticity, could be a considerable factor in memory consolidation. To test this, we examined the timing of changes in PC excitability through $e x$ vivo recordings after the learning task; at short-, mid-, and long- term time periods. The AP firing frequency of PCs was measured in currentclamp mode through the injection of brief current steps with a membrane potential of $\sim-70 \mathrm{mV}$ (500 ms, from 100 to $500 \mathrm{pA}$ with an increment of $100 \mathrm{pA}$; step interval $4.5 \mathrm{~s})$. In agreement with the results of in vitro experiments (Shim et al., 2017), the firing frequency had decreased $1 \mathrm{~h}$ after training in the WT littermates (Fig. 4A,B). The learning-related intrinsic plasticity was partially recovered at the mid-term time period and fully recovered to a value similar to the sham control at the long-term period. However, the STIM1 ${ }^{\text {PKO }}$ group showed a deficiency in the learning-related intrinsic plasticity throughout the studied periods (Fig. 4C,D). Comparing the results from the different genotypes over the same time period, WT littermates had significantly higher firing frequency in sham controls, as we previously reported (Ryu et al., 2017), but the frequency reversed in the short-term period and gradually recovered over the time period studied (Fig. $4 E-H$ ).

We further asked whether STIM1 ${ }^{\mathrm{PKO}}$ mice would fail to induce LTD of IE (LTDIE). To address this possibility, we performed whole-cell patch-clamp recordings to compare the LTD-IE in the STIM1 ${ }^{\text {PKO }}$ group and the WT littermates. A PF burst protocol (7 pulses at $100 \mathrm{~Hz}$ PF burst followed by a single CF stimulation) (Shim et al., 2017) was introduced to induce PC synaptic and intrinsic plasticity in the presence of an inhibitory synaptic transmission inhibitor, picrotoxin. As shown in Figure 2 , both STIM1 ${ }^{\mathrm{PKO}}$ and the WT groups showed normal induction of PF-PC LTD (Fig. 5A). However, the magnitude of the intrinsic plasticity was weaker in the STIM1 ${ }^{\mathrm{PKO}}$ group than in the WT group. Interestingly, the reduction in the excitability following LTD induction was recovered 40 min after the induction in the STIM1 ${ }^{\mathrm{PKO}}$ mice; whereas in the WT littermates, LTD-IE was elicited and developed further (Fig. $5 B$ ). Given the notion that the intrinsic plasticity of cerebellar PCs amplifies the modification of synaptic weight to properly project the learned signal from the PCs to their relay neurons (Shim et al., 2017), our observation may imply that the impairment of intrinsic plasticity results in dysfunctional plasticity induction in the $\mathrm{VN}$ neurons. Because intrinsic plasticity was almost restored $40 \mathrm{~min}$ after plasticity induction in the STIM1 ${ }^{\mathrm{PKO}}$ group (Fig. $5 B$ ), we expect that the learning-related intrinsic plasticity may be already abolished within $1 \mathrm{~h}$ after training. Together, we conclude that intrinsic plasticity of the cerebellar PCs is involved in long-lasting reduction of cerebellar cortical activity, and may thereby contribute to VOR memory consolidation.

Appropriate synaptic and intrinsic plasticity of VN neurons requires intrinsic plasticity of cerebellar PC

We observed an impairment of intrinsic plasticity in the cerebellar PCs of the STIM1 ${ }^{\mathrm{PKO}}$ group through in vitro and ex vivo 

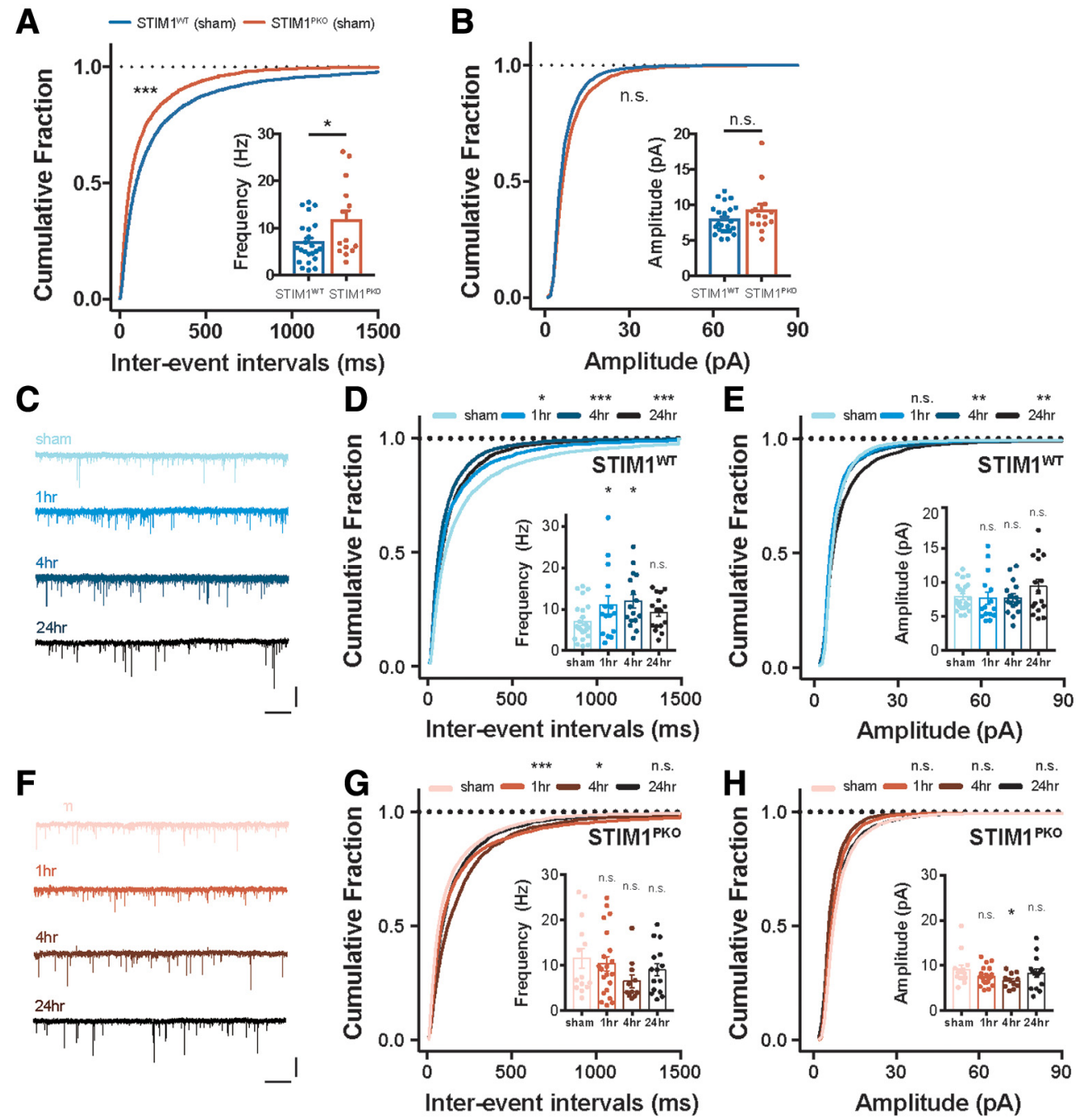

Figure 6. VOR gain-up learning induced LTP of the excitatory input in VN neurons. $A$, Frequency of synaptic transmission in VN neurons from WT littermates ( $n=23$, blue) and STIM1 $1^{\text {PKO }}$ mice $\left(n=14\right.$, red). The cumulative fraction of IEl and bar graph (inset) of sEPSC frequency indicated that frequency of SEPSC was higher in STIM1 ${ }^{\text {PKO }}$ compared with WT littermates (cumulative plot, $p<0.001$; bar graph, $p=0.032$ ). B. Amplitude of $\mathrm{sEPSC}$ in VN neurons from WT littermates (blue) and STIM ${ }^{\mathrm{PKO} 0}$ mice (red). The cumulative fraction of amplitude and bar graph (inset) of $s$ EPSC frequency indicated that amplitude of SEPSC was not changed in STIM1 ${ }^{\mathrm{PKO}}$ compared with WT littermates (cumulative plot, $p=0.180$; bar graph, $p=0.161$ ). C, Representative $\mathrm{SEPSC}$ traces of WT group at each time point. Calibration: 25 pA, 1 s. D, IEl of sEPSC in WT mice (sham, $n=23 ; 1 \mathrm{~h}, n=15 ; 4 \mathrm{~h}, n=16 ; 24 \mathrm{~h}, n=16$ ). The cumulative distributions of IEl were leftshifted after learning $(1 \mathrm{~h}, p=0.019 ; 4 \mathrm{~h}, p<0.001 ; 24 \mathrm{~h}, p<0.001)$. The mean frequency of $\mathrm{sEPSC}$ was significantly potentiated at $4 \mathrm{~h}$ after training (inset; $4 \mathrm{~h}, p=0.035)$. Although 1 and $24 \mathrm{~h}$ groups were significant in cumulative plot, these groups were not statistically significant in mean value (inset; $1 \mathrm{~h}, p=0.116 ; 24 \mathrm{~h}, p=0.503$ ). E, Amplitude of sEPSC in WT mice. The cumulative distribution was significantly right-shifted only at $24 \mathrm{~h}$ after learning $(1 \mathrm{~h}, p=0.281 ; 4 \mathrm{~h}, p=0.994 ; 24 \mathrm{~h}, p=0.002)$. There was trend of potentiation at $24 \mathrm{~h}$ after training, but over-

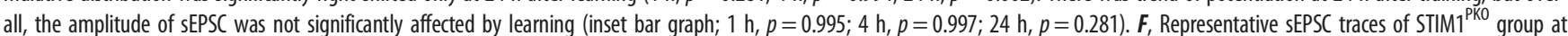
each time point. Calibration: 25 pA, 1 s. G, IEI of SEPSC in STIMP ${ }^{\text {PKO }}$ mice (sham, $n=14 ; 1 \mathrm{~h}, n=21 ; 4 \mathrm{~h}, n=11 ; 24 \mathrm{~h}, n=15$ ). In contrast to WT littermates, the cumulative distribution was significantly right-shifted at 1 and $4 \mathrm{~h}$ after learning, which is opposite direction of WT littermates ( $1 \mathrm{~h}, p<0.001 ; 4 \mathrm{~h}, p=0.040 ; 24 \mathrm{~h}, p=0.408)$. The mean frequency of sEPSC was not significantly altered after learning (inset bar graph; $1 \mathrm{~h}, p=0.921 ; 4 \mathrm{~h}, p=0.162 ; 24 \mathrm{~h}, p=0.617$ ). $\boldsymbol{H}$, Cumulative plots of amplitude of sEPSC in STIMPKO mice. The cumulative distribution was not significantly changed after learning $(1 \mathrm{~h}, p=0.468 ; 4 \mathrm{~h}, p=0.699 ; 24 \mathrm{~h}, p=0.906)$. The amplitude of sEPSC was not significantly changed after learning (inset bar graph; $1 \mathrm{~h}, p=0.528 ; 4 \mathrm{~h}$, $p=0.076 ; 24 \mathrm{~h}, p=0.756)$. $\boldsymbol{A}, \boldsymbol{B}, \boldsymbol{D}, \boldsymbol{E}, \boldsymbol{G}, \boldsymbol{H}$, Kolmogorov-Smirnov test was used for comparing cumulative plots. $\boldsymbol{A}, \boldsymbol{B}$, Unpaired $t$ test was used for inset bar graphs. $\boldsymbol{D}, \boldsymbol{E}, \boldsymbol{G}, \boldsymbol{H}, 0$ ne-way ANOVA with post hoc Dunnett test was used for inset bar graphs. Asterisks at each time point were calculated by comparing with sham groups. Error bars indicate $S E M$. ${ }^{*} p<0.05$; ${ }^{* *} p<0.01 ; * * * 00.001$. n.s., not significant.

recordings. This suggests that memory consolidation requires the sustained intrinsic plasticity of the cerebellar PCs. A large population of VN neurons receive information from floccular PCs (Shin et al., 2011; Matsuno et al., 2016). Furthermore, the output of cerebellar PCs serves as an instructive signal for the neuronal plasticity between MFs and VN neurons (Shutoh et al., 2006; Porrill and Dean, 2007; McElvain et al., 2010; Clopath et al., 2014; Yamazaki et al., 2015). Thus, we hypothesized that the impairment of intrinsic plasticity in the cerebellar cortex that was observed in STIM1 ${ }^{\mathrm{PKO}}$ mice would lead to inappropriate alteration of VN neuron activity following VOR adaptation. To address this, we performed ex vivo recordings to investigate spontaneous synaptic transmission after the learning task during three distinct time periods; short-term, mid-term, and longterm. In the sham group, the frequency of sEPSC STIM1 ${ }^{\mathrm{PKO}}$ mice showed higher sEPSC frequency compared with the WT littermate, whereas amplitude was not significantly different between the genotypes (Fig. 6A,B). These results imply that the homeostatic scaling in the $\mathrm{VN}$ neurons is due to the reduction of PC excitability in the STIM1 ${ }^{\text {PKO }}$ group (Fig. $4 E$ ). Intriguingly, synaptic transmission was found to be potentiated after VOR adaptation in the WT littermates throughout the periods of study 
A

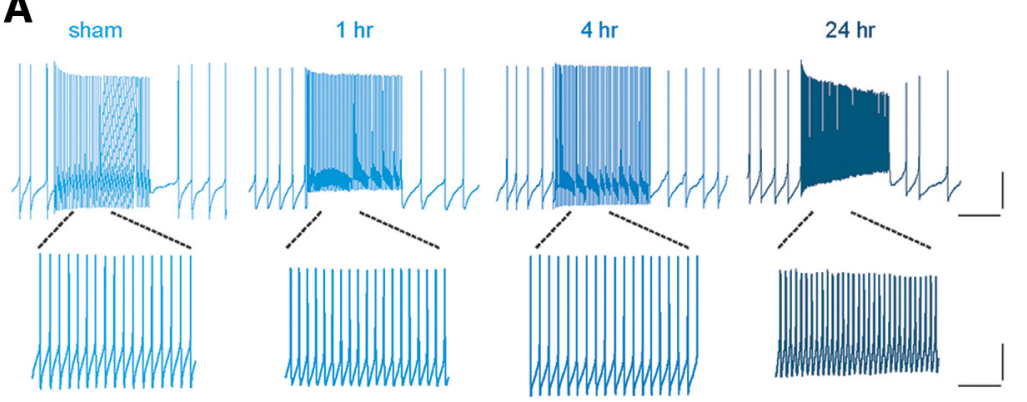

B

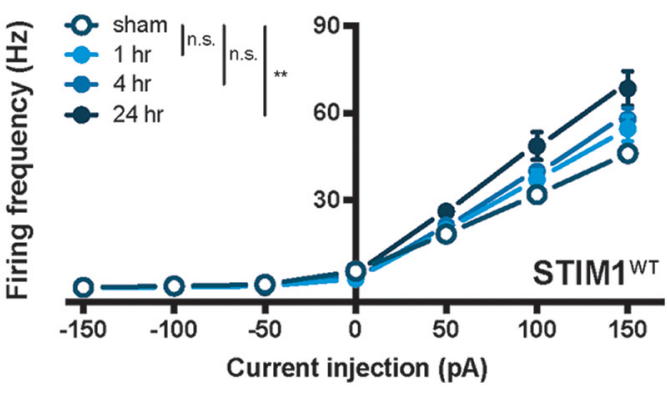

C
Sham

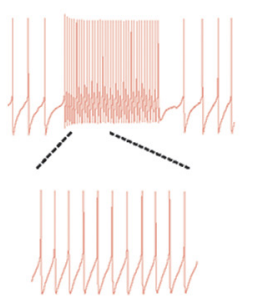

$1 \mathrm{hr}$

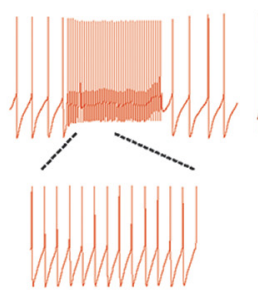

$4 \mathrm{hr}$

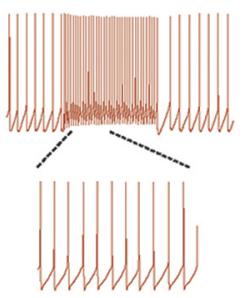

D

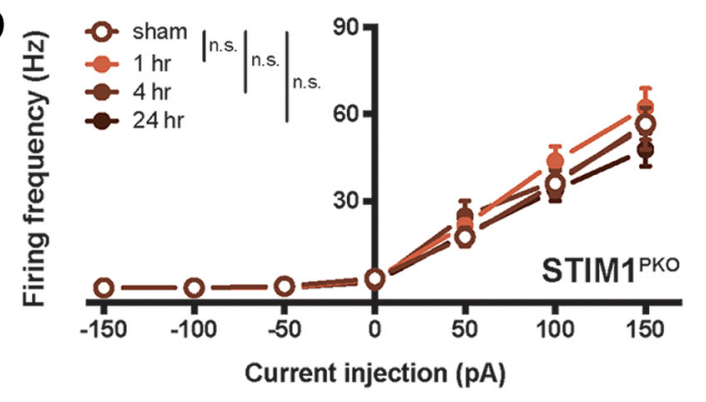

E

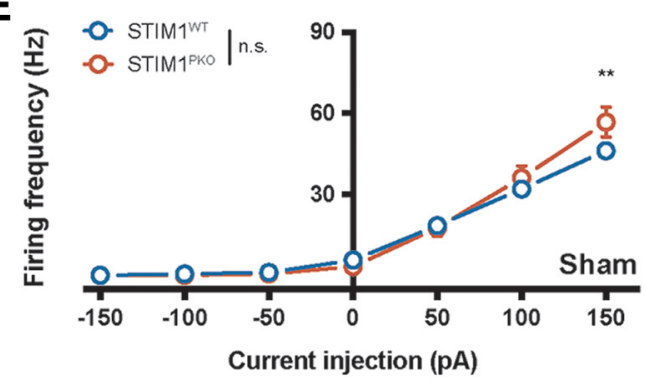

F

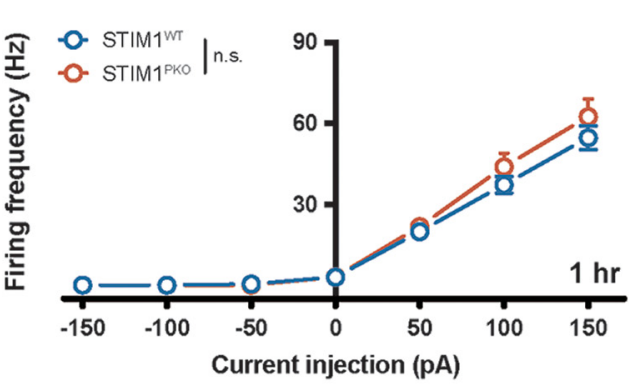

G

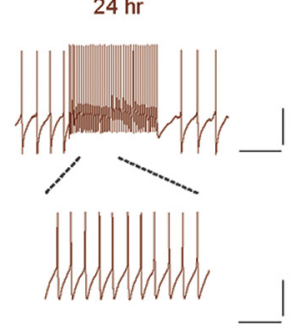

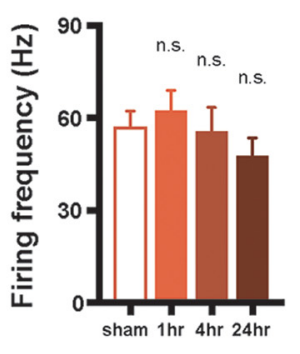

H

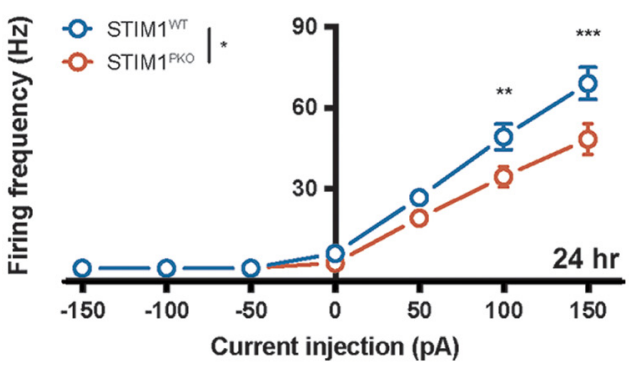

Figure 7. VOR gain-up learning induced potentiation of IE in VN neurons. A, Representative traces from whole-cell recordings of the WT group at each time point. Calibration (top): $20 \mathrm{mV}$, $500 \mathrm{~ms}$. Calibration (bottom): $20 \mathrm{mV}, 125 \mathrm{~ms}$. B. The excitability of VN neurons in WT littermates. VOR adaptation significantly potentiated gain of the VN neurons in response to square-wave current injection ranging from $-150 \mathrm{pA}$ to $150 \mathrm{pA}$ for $1 \mathrm{~s}$ (sham vs $1 \mathrm{~h}, p=0.319$; sham vs $4 \mathrm{~h}, p=0.072$; sham vs $24 \mathrm{~h}, p=0.002$, left; sham, $n=23 ; 1 \mathrm{~h}, n=16 ; 4 \mathrm{~h}, n=38 ; 24 \mathrm{~h}$, $n=19)$. Excitability in $150 \mathrm{pA}$ injection was elevated but not significantly at $4 \mathrm{~h}(p=0.082)$ and significantly increased at $24 \mathrm{~h}(p=0.002)$ after training. $C$, Representative traces from wholecell recordings of WT group at each time point. Calibration (top): $20 \mathrm{mV}, 500 \mathrm{~ms}$. Calibration (bottom): $20 \mathrm{mV}, 125 \mathrm{~ms}$. D. Excitability of VN neurons in STIM1 ${ }^{\text {PKO }}$ mice. There was no alteration of excitability after learning (sham vs $1 \mathrm{~h}, p=0.422$; sham vs $4 \mathrm{~h}, p=0.801$; sham vs $24 \mathrm{~h}, p=0.493$, left; sham, $n=17 ; 1 \mathrm{~h}, n=25 ; 4 \mathrm{~h}, n=15 ; 24 \mathrm{~h}, n=15$ ), and no significant changes in $150 \mathrm{pA}$ injection as well ( $1 \mathrm{~h}, p=0.864 . ; 4 \mathrm{~h}, p=0.999 ; 24 \mathrm{~h}, p=0.697)$. $\boldsymbol{E}$, Overall, the gain responses of VN neurons from STIM1 ${ }^{\text {PKO }}$ mice $(n=16)$ were not significantly different from WT littermates $(n=23, p=0.423)$; but at $150 \mathrm{pA}$ injection, $S T I M 1^{\mathrm{PKO}}$ mice showed higher excitability than WT littermates $(p=0.003)$. $\boldsymbol{F}$, At the short-term period, the excitability of VN neurons of the WT $(n=16)$ had slightly increased, whereas the excitability of STIM1 ${ }^{\text {PKO }}(n=25)$ was unchanged. Statistical difference had disappeared $(p=0.428)$. G, At $4 \mathrm{~h}$ after learning, the excitability of VN neurons of the WT $(n=38)$ increased more, and that of STIMP ${ }^{\mathrm{PKO}}(n=15)$ was again unchanged. 10 curves of both groups are overlapped $(p=0.759)$. $\boldsymbol{H}$, As the excitability of WT littermates $(n=19)$ became much higher at the long-term period, the WT group showed significant higher frequency than STIM1 ${ }^{\text {PKO }}$ group $(n=15)(p=0.016)$. At 100 and $150 \mathrm{pA}$ injection, statistical significance was $0.005(100 \mathrm{pA})$ and $<0.001(150 \mathrm{pA})$ by post hoc Sidak test. B, D-H, Two-way repeated-measures ANOVA with post hoc Sidak test was used for injected current-frequency and bar graphs. $B, D$, One-way ANOVA with post hoc Dunnett test was used for bar graphs. Asterisks at each time points were calculated by comparing with sham groups. Error bars indicate SEM. ${ }^{*} p<0.05 ;{ }^{* *} p<0.01 ;{ }^{* * *} p<0.001$. n.s., not significant. 
(Fig. 6C-E). Although the increase in the mean frequency of sEPSC after training seemed to be restored at the long-term period, the cumulative distribution of the IEIs was found to be left-shifted throughout the periods of study (Fig. 6D). The cumulative fraction of the sEPSC amplitude was especially right-shifted at the longterm period, indicating that the proportion of increased glutamatergic synaptic events was enhanced during this period (Fig. 6E). However, the mean value was not significantly different compared with that of the sham control (Fig. 6E, inset). These results indicate that VOR gain-up learning induces LTP at the MF-VN synapse, in line with the previous study (Boyden et al., 2006). In contrast to the results presented from the WT littermates, the STIM1 ${ }^{\text {PKO }}$ group showed a depression of sEPSC frequency in the cumulative distribution of short-term and mid-term time periods that continuously recovered to baseline (Fig. 6G). However, the mean frequency was not significantly altered between the periods of study (Fig. 6G, inset). The amplitude of sEPSC was slightly left-shifted in the short- and midterm time periods, and the mean amplitude of the mid-term time period was significantly lower than that of the sham group (Fig. 6H). In light of previous reports which have suggested that cerebellar PC activity contributes to MF-VN plasticity (McElvain et al., 2010; Matsuno et al., 2016), we speculated that the synaptic plasticity at MF-VN synapse is aberrant in the STIM1 ${ }^{\text {PKO }}$ group due to the absence of PC intrinsic plasticity.

Furthermore, we asked whether the intrinsic plasticity of cerebellar PCs is also required for the adequate induction of intrinsic plasticity in VN neurons because VOR training involves a change in the excitability as well as synaptic transmission (Shutoh et al., 2006; Carcaud et al., 2017). To answer this, the gain responses were measured through the injection of squarewised somatic depolarizing current into VN neurons throughout the periods after the learning task. The VN neurons of the STIM1 ${ }^{\mathrm{PKO}}$ group showed higher firing frequency in response to the current injection than that in the WT littermates in the sham group (Fig. $7 E$ ). Interestingly, VOR training elicited intrinsic plasticity of the VN neurons in the WT littermates (Fig. $7 A, B$ ), whereas there was no alteration of the gain responses in the STIM1 ${ }^{\mathrm{PKO}}$ group (Fig. $7 C, D$ ). The excitability of the $\mathrm{VN}$ neurons gradually increased over the studied time periods, and the intrinsic plasticity was maintained $24 \mathrm{~h}$ after training (Fig. $7 B$ ). The difference between the sham groups of both genotypes was decreased during the short- and the mid-term time period, and finally reversed with statistical significance at the long-term time period (Fig. $7 E-H$ ). To clarify whether the neural plasticity in the VN neurons was affected by KO of STIM1 in PCs, we delivered the conventional protocol for induction of LTP in VN neurons $(100 \mathrm{~Hz}$ synaptic stimulation for $550 \mathrm{~ms}$ paired with $250 \mathrm{~ms}$ hyperpolarization at the beginning of synaptic stimulation)
(McElvain et al., 2010). The VN neurons from the WT and STIM1 $^{\text {PKO }}$ groups exhibited potentiation of the synaptic weight and excitability (Fig. 8B,C), implying that absence of LTP and LTP-IE in VN neurons after training may not be derived from nonspecific occlusion of higher baseline firing rates in the STIM $1^{\text {PKO }}$. Together with modification of synaptic weight and intrinsic properties in $\mathrm{VN}$ neurons, we suggest that the intrinsic plasticity of the cerebellar PCs following VOR adaptation could induce the proper forms of neuronal plasticity in VN neurons, corresponding to specific behavior, underlying consolidation of motor memory.

\section{Discussion}

Here, we demonstrate a role of intrinsic plasticity of cerebellar PCs in consolidation of motor learning. In light of previous study (Shim et al., 2017), we find that VOR gain-up training induces PFPC LTD and concomitant reduction of IE of the PCs, the LTD-IE. Furthermore, this VOR gain-up adaptation causes potentiation of the synaptic weight and IE in VN neurons, which supports the multiple plasticity mechanism (Boyden et al., 2004). In this study, we highlight the link between plasticity in both cerebellar cortex and brainstem. The activity-dependent intrinsic plasticity of the cerebellar PCs may provide an instructive signal to the VN neurons, thereby contributing to the systems consolidation.

Cerebellar motor learning has been thought to be implanted by synaptic plasticity in the multiple sites of the cerebellar 
A

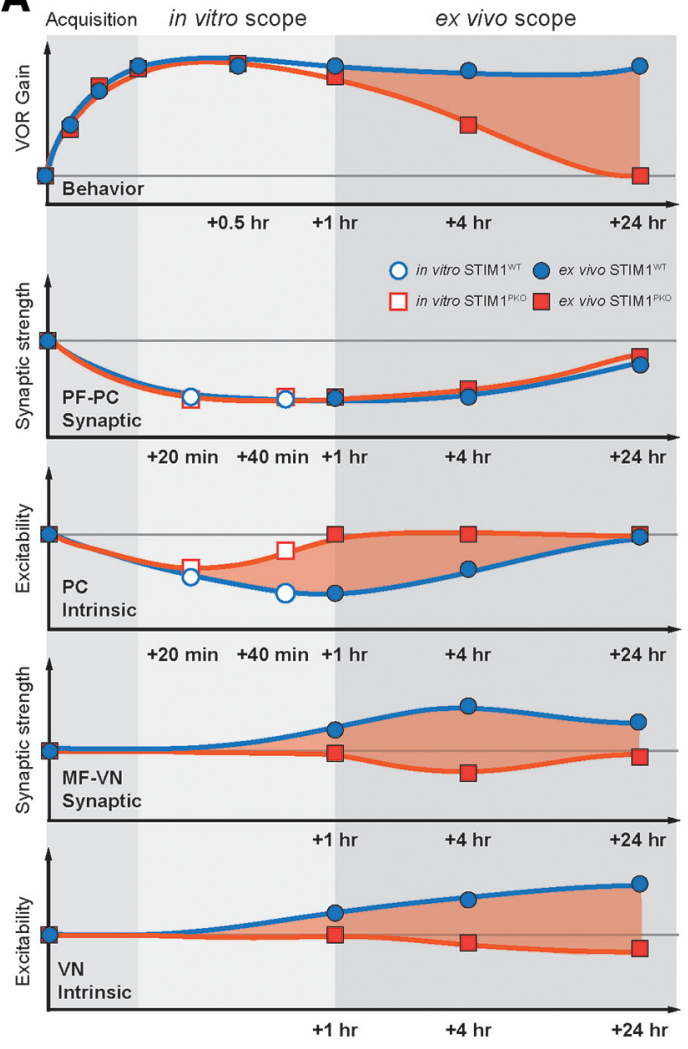

B
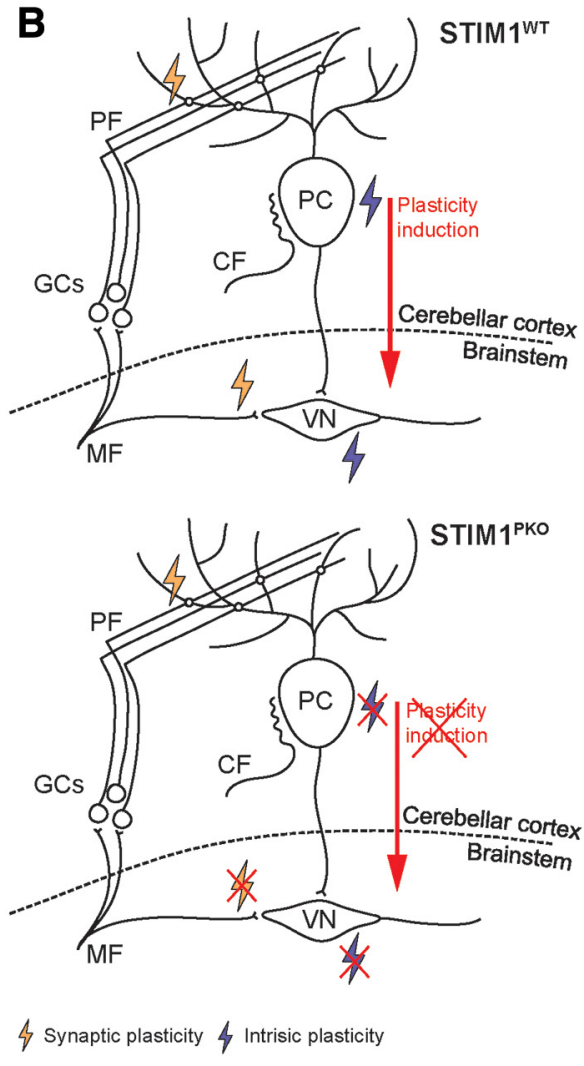

Figure 9. Schematic illustration for memory trace of VOR memory. A, Summary of behavioral tests and in vitro and ex vivo recordings showing temporal order of the memory retention and neural plasticity in PCS and VN neurons. Red shade represents differences between WT and STIM1 ${ }^{\mathrm{PKO}}$ mice. VOR memory retention level is maintained over $1 \mathrm{~d}$, whereas the motor memory is declined at mid-term period (1-4 h) and long-term (24 h) in STIM1 ${ }^{\mathrm{PKO}}$ mice. Bottom, Alterations of the neural activity corresponding to each period. There is no difference in PF-PC synaptic plasticity between WT and STIM1 ${ }^{\mathrm{PKO}}$ mice. However, learning-induced LTD-IE is abolished within an hour in STIMP ${ }^{\mathrm{PKO}}$, and the difference in PC intrinsic plasticity between groups may lead to MF-VN synaptic plasticity and intrinsic plasticity of VN neurons (red shade). Furthermore, the peak difference of each plot seems to move from 1 to $24 \mathrm{~h}$ after learning, indicating that the plasticity in cerebellar PCs and VN neurons is connected in order. Thus, we speculate that PC intrinsic plasticity, which plays a role in linking between the cerebellum and VN, but not PF-PC synaptic plasticity, underlies behavioral difference between WT littermates and STIM1 ${ }^{\text {PKO }}$ (top, red shade). B, Schematic illustration of neural circuit for VOR memory storage shown in WT (top) and $\mathrm{STIM}^{\mathrm{PKO}}$ mice (bottom). For successful memory acquisition and storage, four different types of neural plasticity are necessary (synaptic and intrinsic plasticity in the PCs and VN neurons). Especially, intrinsic plasticity of $\mathrm{PC}$ has an important role to induce plasticity in the brainstem (top). When $\mathrm{PC}$ intrinsic plasticity is abolished, synaptic and intrinsic plasticity in VN neurons are impaired, thereby failing to induce plasticity in the brainstem (bottom).

circuits, including both cerebellar cortex and brainstem (Boyden et al., 2004; Gao et al., 2012; Ito, 2013). Most importantly, we elucidate an unprecedented role of intrinsic plasticity of cerebellar PCs in the VOR memory circuit by using behavioral assessment and electrophysiological recordings with memory consolidationdeficient mice model (Fig. 1). The data we presented here insist that intrinsic plasticity of PC would link between the distributed plasticity occurs throughout the memory circuits. Impairment of the PC intrinsic plasticity in the STIM1 ${ }^{\mathrm{PKO}}$ mice accompanies lack of plasticity in the VN neurons, presumably resulting in the memory consolidation deficit. The VN neurons in the STIM1 ${ }^{\mathrm{PKO}}$ mice are endowed with synaptic and intrinsic plasticity in vitro (Fig. 8), implying that the learning-related alteration of excitability in the PCs might serve as an instructive signal to induce appropriate plasticity induction in VN neurons (Fig. 9). These results support previous expectations that PC activity can affect the synaptic and intrinsic plasticity induction in VN neurons (McElvain et al., 2010). Collectively, our results reconcile two long-standing hypotheses by providing experimental evidence for the induction of multiple forms of plasticity through VOR adaptation in both the cerebellar cortex and the brainstem.

It has been speculated that VOR memory is formed in the cerebellar cortex and then transferred into the neurons in the VN in late phase adaptation for VOR gain (Shutoh et al., 2006;
Ito, 2013). This prediction implies that the temporal order between PC and VN plasticity has to be considered in memory processing. In our results, the $\mathrm{VN}$ plasticity is induced at a relatively later period than the plasticity in the PCs, and it indicates two major aspects. One is that PF-PC LTD contributes to memory acquisition, and the other is that the consequent induction of plasticity in VN neurons encodes long-term memory storage. Our data indicate that impaired intrinsic plasticity of the cerebellar PCs would fail to influence the plasticity of VN and disrupt long-term memory storage. This supports the theory that intrinsic plasticity of PCs connects two distinct brain regions and shapes the information flow from the cerebellar cortex to the brainstem. The temporal order of plasticity at multiple sites may reflect the loci of memory storage. The ex vivo recordings we presented here were executed at distinct time points: short-term $(\sim 1 \mathrm{~h})$, mid-term $(\sim 4 \mathrm{~h})$, and long-term $(\sim 24 \mathrm{~h})$ periods after learning. At the short-term period, the VOR adaptation curve and synaptic plasticity were not impaired in the memory consolidation deficient mouse model, although intrinsic plasticity was abolished (Fig. 9). These results indicate that the memory acquisition may require synaptic plasticity in the cerebellar cortex, but not intrinsic plasticity. Rather, the aspects of the memory retention and deficiency of intrinsic plasticity in STIM1 ${ }^{\mathrm{PKO}}$ lead us to assume that the learning-related alteration in PC excitability 
might instruct the plasticity of VN neurons. Consistent with previous implications, our results suggest that the plasticity of $\mathrm{VN}$ neurons occurs within $4 \mathrm{~h}$ after learning (Kassardjian et al., 2005; Shutoh et al., 2006; Okamoto et al., 2011a). Synergies between synaptic and intrinsic plasticity may provide an instructive signal to convey the learned information into the $\mathrm{VN}$ at the mid-term $(\sim 4 \mathrm{~h})$ period. Intriguingly, synaptic plasticity in the VN neurons is observed slightly later than intrinsic plasticity of the PC. Additionally, there is another slight delay for the $\mathrm{VN}$ intrinsic plasticity to reach its peak (Figs. 6,7). These results indicate that sequential flow of information from the cerebellar cortex to the subcortical region is responsible for memory processing.

We were not able to record changes in the synaptic weight selectively from the synapses that are engaged in VOR learning. So for, it has yet to be explored that the spatial distribution of the synaptic plasticity between the PCs and the dendrite of VN neurons after VOR training. Several studies have suggested that the polarity of the synaptic plasticity in a single neuron and/or single dendrite could be heterogeneous throughout the dendritic tree (Royer and Paré, 2003; Ohtsuki et al., 2012; Zang et al., 2018). In the amygdala neurons, the spatial profile of the synaptic plasticity has been shown as Mexican-hat distribution, a certain type of plasticity region in the dendrite surrounded by the opposite direction of changes (Royer and Paré, 2003). Thus, this phenomenon after synaptic activation in acute slice preparation might take place in the synaptic plasticity of PCs and VN neurons after VOR training. In this study, we nevertheless measured the averaged synaptic strength and observed an overall reduction of synaptic activity after training. To measure the synaptic weight altered after VOR training selectively, the diversity and spatial profile of the synaptic plasticity during VOR learning are to be further addressed.

It is widely believed that the plasticity of neuronal excitability is involved in the cellular mechanism for memory storage (Daoudal and Debanne, 2003; Zhang and Linden, 2003). In particular, intrinsic plasticity of cerebellar PCs shows features in the cerebellar memory circuits that are distinct from other types of neurons. In the neurons in the amygdala and hippocampus, learning-related neurons show higher excitability (Zhou et al., 2009), and the depolarization of the membrane potential of these cells enables promoting further synaptic plasticity (Ramakers and Storm, 2002; Watanabe et al., 2002; Hyun et al., 2015). Thus, these excitable neurons form a stable connection by strengthening the synaptic weight in the given neural network, thereby consolidating the memory. In contrast, a previous study suggested that intrinsic plasticity of PCs occludes the subsequent induction of PF-PC synaptic plasticity (Belmeguenai et al., 2010). Hence, the plasticity of excitability may ensure that synaptic activity remains within a physiological limit by restricting further synaptic plasticity and adjusting the impact of PF activation on the output of PCs. In addition, our data show that there is no significant difference in the magnitude of synaptic plasticity at the PF-PC synapses between the WT littermate group and STIM1 ${ }^{\text {PKO }}$ group (Fig. $5 A$ ), although the excitability is lower in the STIM1 ${ }^{\mathrm{PKO}}$ group than the WT group (Fig. 4E). Furthermore, the learning curve of VOR gain-up training was comparable between STIM1 ${ }^{\text {PKO }}$ and WT littermates (Fig. 1D), despite noticeable differences of basal excitability in the PCs among genotypes (Fig. $4 E$ ). Together, these results suggest that the basal membrane excitability in PCs is not thought to be correlated with the synaptic plasticity induction or the magnitude of synaptic plasticity. Considering the changes of neuronal activity in $\mathrm{VN}$ neurons over time, $\sim 4 \mathrm{~h}$ may be a critical period to induce neural plasticity in the $\mathrm{VN}$ neurons. Interestingly, PC intrinsic plasticity was found to be significantly decayed within $4 \mathrm{~h}$ after learning (Fig. 4B). We previously described that the concurrence of bidirectional synaptic and intrinsic plasticity may synergistically shape the cerebellar PC output (Shim et al., 2017). Most recently, synaptic LTD was found to be insufficiently reflected by spike output in STIM1 ${ }^{\text {PKO }}$ mice because of lack of intrinsic plasticity, indicating that synergies between synaptic and intrinsic plasticity may play a critical role in determining the optimal ranges of PC output onto the downstream neurons (Shim and Kim, 2019). In this scenario, impairment of PC intrinsic plasticity shown in STIM1 ${ }^{\text {PKO }}$ would break down the synergies between synaptic and intrinsic plasticity, thereby manifesting impairment of plasticity in VN neurons. In addition to individual activity of PC or the synergistic effect, the temporal synchrony of PC output has been regarded as a considerable factor that contributes to information delivery from PC to deep cerebellar nuclei (Person and Raman, 2011). Accordingly, our data support the idea that activity-dependent alteration of synaptic weight and excitability in PCs play a role in providing an instructive signal contributing to plasticity in VN neurons. In conclusion, we suggest that learning-related intrinsic plasticity may amplify alterations of synaptic transmission, resulting in the synergistic modulation of the net output of PCs to store acquired memory successfully.

\section{References}

Belmeguenai A, Hosy E, Bengtsson F, Pedroarena CM, Piochon C, Teuling E, He Q, Ohtsuki G, De Jeu MT, Elgersma Y, De Zeeuw CI, Jörntell H, Hansel C (2010) Intrinsic plasticity complements long-term potentiation in parallel fiber input gain control in cerebellar Purkinje cells. J Neurosci 30:13630-13643.

Boyden ES, Katoh A, Pyle JL, Chatila TA, Tsien RW, Raymond JL (2006) Selective engagement of plasticity mechanisms for motor memory storage. Neuron 51:823-834.

Boyden ES, Katoh A, Raymond JL (2004) Cerebellum-dependent learning: the role of multiple plasticity mechanisms. Annu Rev Neurosci 27:581609.

Carcaud J, França de Barros F, Idoux E, Eugène D, Reveret L, Moore LE, Vidal PP, Beraneck M (2017) Long-lasting visuo-vestibular mismatch in freely-behaving mice reduces the vestibulo-ocular reflex and leads to neural changes in the direct vestibular pathway. eNeuro 4:ENEURO.029016.2017-16.

Clopath C, Badura A, De Zeeuw CI, Brunel N (2014) A cerebellar learning model of vestibulo-ocular reflex adaptation in wild-type and mutant mice. J Neurosci 34:7203-7215.

Daoudal G, Debanne D (2003) Long-term plasticity of intrinsic excitability: learning rules and mechanisms. Learn Mem 10:456-465.

Gao Z, van Beugen BJ, De Zeeuw CI (2012) Distributed synergistic plasticity and cerebellar learning. Nat Rev Neurosci 13:619-635.

Hyun JH, Eom K, Lee KH, Bae JY, Bae YC, Kim MH, Kim S, Ho WK, Lee SH (2015) Kv1.2 mediates heterosynaptic modulation of direct cortical synaptic inputs in CA3 pyramidal cells. J Physiol 593:3617-3643.

Inoshita T, Hirano T (2018) Occurrence of long-term depression in the cerebellar flocculus during adaptation of optokinetic response. Elife 7:113.

Ito M (1982) Cerebellar control of the vestibulo-ocular reflex-around the flocculus hypothesis. Annu Rev Neurosci 5:275-296.

Ito M (2013) Error detection and representation in the olivo-cerebellar system. Front Neural Circuits 7:1.

Jang DC, Shim HG, Kim SJ (2019) Intrinsic plasticity of cerebellar Purkinje cells in motor learning circuits. Pflugers Arch - Eur J Physiol 471:927934.

Kakegawa W, Katoh A, Narumi S, Miura E, Motohashi J, Takahashi A, Kohda K, Fukazawa Y, Yuzaki M, Matsuda S (2018) Optogenetic control of synaptic AMPA receptor endocytosis reveals roles of LTD in motor learning. Neuron 99:985-998.e986.

Kandel ER, Dudai Y, Mayford MR (2014) The molecular and systems biology of memory. Cell 157:163-186. 
Kassardjian CD, Tan YF, Chung JY, Heskin R, Peterson MJ, Broussard DM (2005) The site of a motor memory shifts with consolidation. J Neurosci 25:7979-7985.

Matsuno H, Kudoh M, Watakabe A, Yamamori T, Shigemoto R, Nagao S (2016) Distribution and structure of synapses on medial vestibular nuclear neurons targeted by cerebellar flocculus Purkinje cells and vestibular nerve in mice: light and electron microscopy studies. PLoS One 11: e0164037.

McElvain LE, Bagnall MW, Sakatos A, du Lac S (2010) Bidirectional plasticity gated by hyperpolarization controls the gain of postsynaptic firing responses at central vestibular nerve synapses. Neuron 68:763-775.

Ohtsuki G, Piochon C, Adelman JP, Hansel C (2012) SK2 channel modulation contributes to compartment-specific dendritic plasticity in cerebellar Purkinje cells. Neuron 75:108-120.

Okamoto T, Endo S, Shirao T, Nagao S (2011a) Role of cerebellar cortical protein synthesis in transfer of memory trace of cerebellum-dependent motor learning. J Neurosci 31:8958-8966.

Okamoto T, Shirao T, Shutoh F, Suzuki T, Nagao S (2011b) Post-training cerebellar cortical activity plays an important role for consolidation of memory of cerebellum-dependent motor learning. Neurosci Lett 504:5356.

Person AL, Raman IM (2011) Purkinje neuron synchrony elicits time-locked spiking in the cerebellar nuclei. Nature 481:502-505.

Porrill J, Dean P (2007) Cerebellar motor learning: when is cortical plasticity not enough? PLoS Comput Biol 3:1935-1950.

Ramakers GM, Storm JF (2002) A postsynaptic transient $\mathrm{K}^{+}$current modulated by arachidonic acid regulates synaptic integration and threshold for LTP induction in hippocampal pyramidal cells. Proc Natl Acad Sci USA 99:10144-10149.

Royer S, Paré D (2003) Conservation of total synaptic weight through balanced synaptic depression and potentiation. Nature 422:518-522.

Ryu C, Jang DC, Jung D, Kim YG, Shim HG, Ryu HH, Lee YS, Linden DJ, Worley PF, Kim SJ (2017) STIM1 regulates somatic $\mathrm{Ca}^{2+}$ signals and intrinsic firing properties of cerebellar Purkinje neurons. J Neurosci 37:8876-8894

Ryu HH, Kim T, Kim JW, Kang M, Park P, Kim YG, Kim H, Ha J, Choi JE, Lee J, Lim CS, Kim CH, Kim SJ, Silva AJ, Kaang BK, Lee YS (2019) Excitatory neuron-specific SHP2-ERK signaling network regulates synaptic plasticity and memory. Sci Signal 12:eaau5755.

Schonewille M, Belmeguenai A, Koekkoek SK, Houtman SH, Boele HJ, Van Beugen BJ, Gao Z, Badura A, Ohtsuki G, Amerika WE, Hosy E, Hoebeek FE, Elgersma Y, Hansel C, De Zeeuw CI (2010) Purkinje cell-specific knockout of the protein phosphatase PP2B impairs potentiation and cerebellar motor learning. Neuron 67:618-628.

Schonewille M, Gao Z, Boele HJ, Veloz MF, Amerika WE, Simek AA, De Jeu MT, Steinberg JP, Takamiya K, Hoebeek FE, Linden DJ, Huganir RL, De Zeeuw CI (2011) Reevaluating the role of LTD in cerebellar motor learning. Neuron 70:43-50.

Schonewille M, Luo C, Ruigrok TJ, Voogd J, Schmolesky MT, Rutteman M, Hoebeek FE, De Jeu MT, De Zeeuw CI (2006) Zonal organization of the mouse flocculus: physiology, input, and output. J Comp Neurol 497:670682.

Shim HG, Jang DC, Lee J, Chung G, Lee S, Kim YG, Jeon DE, Kim SJ (2017) Long-term depression of intrinsic excitability accompanied by synaptic depression in cerebellar Purkinje cells. J Neurosci 37:5659-5669.

Shim HG, Lee YS, Kim SJ (2018) The emerging concept of intrinsic plasticity: activity-dependent modulation of intrinsic excitability in cerebellar Purkinje cells and motor learning. Exp Neurobiol 27:139-154.

Shim HG, Kim SJ (2019) Synaptic and intrinsic plasticity coordinate spike output in cerebellar Purkinje cells. bioRxiv. Advance online publication. Retrieved August 21, 2019. doi: 10.1101/742577.

Shin M, Moghadam SH, Sekirnjak C, Bagnall MW, Kolkman KE, Jacobs R, Faulstich M, du Lac S (2011) Multiple types of cerebellar target neurons and their circuitry in the vestibulo-ocular reflex. J Neurosci 31:1077610786

Shutoh F, Ohki M, Kitazawa H, Itohara S, Nagao S (2006) Memory trace of motor learning shifts transsynaptically from cerebellar cortex to nuclei for consolidation. Neuroscience 139:767-777.

Watanabe S, Hoffman DA, Migliore M, Johnston D (2002) Dendritic $\mathrm{K}^{+}$ channels contribute to spike-timing dependent long-term potentiation in hippocampal pyramidal neurons. Proc Natl Acad Sci USA 99:8366-8371.

Wulff P, Schonewille M, Renzi M, Viltono L, Sassoè-Pognetto M, Badura A, Gao Z, Hoebeek FE, van Dorp S, Wisden W, Farrant M, De Zeeuw CI (2009) Synaptic inhibition of Purkinje cells mediates consolidation of vestibulo-cerebellar motor learning. Nat Neurosci 12:1042-1049.

Yamazaki T, Nagao S, Lennon W, Tanaka S (2015) Modeling memory consolidation during posttraining periods in cerebellovestibular learning. Proc Natl Acad Sci USA 112:3541-3546.

Zang Y, Dieudonné S, De Schutter E (2018) Voltage- and branch-specific climbing fiber responses in Purkinje cells. Cell Rep 24:1536-1549.

Zhang W, Linden DJ (2003) The other side of the engram: experience-driven changes in neuronal intrinsic excitability. Nat Rev Neurosci 4:885-900.

Zhou Y, Won J, Karlsson MG, Zhou M, Rogerson T, Balaji J, Neve R, Poirazi P, Silva AJ (2009) CREB regulates excitability and the allocation of memory to subsets of neurons in the amygdala. Nat Neurosci 12:1438-1443. 